\title{
Competitive dominance, gang size and the directionality of gang violence
}

\author{
P. Jeffrey Brantingham ${ }^{1 *}$, Matthew Valasik² and George E. Tita ${ }^{3}$
}

\begin{abstract}
Intergroup violence is assumed to play a key role in establishing and maintaining gang competitive dominance. However, it is not clear how competitive ability, gang size and reciprocal violence interact. Does competitive dominance lead to larger gangs, or allow them to remain small? Does competitive dominance lead gangs to mount more attacks against rivals, or expose them to more attacks? We explore a model developed in theoretical ecology to understand communities arranged in strict competitive hierarchies. The model is extended to generate expectations about gang size distributions and the directionality of gang violence. Model expectations are explored with twenty-three years of data on gang homicides from Los Angeles. Gangs may mitigate competitive pressure by quickly finding gaps in the spatial coverage of superior competitors. Competitively superior gangs can be larger or smaller than competitively inferior gangs and a disproportionate source or target of directional violence, depending upon where exactly they fall in the competitive hierarchy. A model specifying the mechanism of competitive dominance is needed to correctly interpret gang size and violence patterns.
\end{abstract}

Keywords: Street gangs, Theoretical ecology, Mathematical modeling, Violent crime, Homicide

\section{Introduction}

Intergroup violence is common in communities with multiple criminal street gangs (Decker 1996; Glowacki et al. 2016; Gravel et al. 2018; Papachristos et al. 2013; White 2013). Violence directed at rivals may satisfy certain instrumental goals of both individual gang members and the gang as a whole, but it may also be central to the construction of individual and group identity (Bannister et al. 2013). In either case, it is reasonable to describe intergroup gang violence as a directional competitive interaction that is meant to benefit one gang (the attacker) at the expense of its rival (the attacked). Directional competitive interactions between gangs are usually imbalanced. Gangs are either net exporters, or net importers of violence (Bichler et al. 2017; Papachristos 2009). Rarely are they perfectly balanced as targets and aggressors over a collection of violent crimes. This paper

\footnotetext{
*Correspondence: branting@ucla.edu

1 Department of Anthropology, University of California Los Angeles,

341 Haines Hall, Los Angeles, CA 90095, USA

Full list of author information is available at the end of the article
}

seeks to understand how and why imbalances exist in intergroup street gang violence.

A leading hypothesis is that imbalances in intergroup violence are tied to differences in competitive ranking between gangs. Papachristos (2009, p. 76), for example, starts with the observation that gang homicides are part of the process whereby individual gang members and gangs as social groups "jockey for positions of dominance." If the attacking gang does indeed benefit more than the attacked in a violent exchange, then gangs that are net exporters of violence should rank higher in a gang community "pecking order" as more influence (e.g., status, reputation, supremacy) accrues to that gang. Street gangs that are net importers of violence should therefore rank lower. However, the direct evidence for competitive dominance hierarchies within communities of gangs is mixed (see Bichler et al. 2017; Gravel et al. 2018; Miller 1958; Papachristos 2009; Randle and Bichler 2017). Papachristos et al. (2013), for example, find little evidence of the specific network topological structures that would be indicative of a strict competitive hierarchy in homicides networks from Chicago and Boston, even though those gangs display large imbalances in the directionality 
of violence. Randle and Bichler (2017), by contrast, see many local dominance relationships in homicide networks in Southern California. Gang size variation and its impact on the directionality of violence offers limited clarification. We might expect large gangs to use their size advantage to maintain a dominant community position by directing more violence at smaller rivals (Vargas 2016). However, large gangs may be just as likely to be net importers of violence as net exporters (Papachristos 2009, pp. 112-113). Large gangs might simply present more abundant and accessible targets for smaller rivals. Of course, we might also conclude that gang size and the directionality of violence are not simple proxies for gang dominance.

A key problem is that we lack a formal theoretical framework that links competitive dominance to empirical patterning in gang size and the directionality of violence. The primary purpose of the present paper is to introduce one such a framework. Our approach builds on the work of ecologist Tilman (1994). Tilman sought to understand how inferior competitors could stably coexist in the face of pressure from superior competitors who possess an absolute ability to displace them from any contested site (see also Nee and May 1992). Tilman found that inferior competitors could persist if they are able to find and exploit gaps in the spatial range occupied by superior competitors. We map Tilman's ecological model to the study of spatial distribution of gang activities and, in the process, repeat many of Tilman's key observations. Our primary contribution is to generate expectations about how gang size and the directionality of violence should vary given differences in the position of gangs within a competitive hierarchy as well as between-gang differences in the rate of spread and cessation of gang activity across space. We examine the model with data on gang size diversity and the directionality of gang homicides in a community of gangs in Los Angeles sampled over a twenty-three-year period from 1990 to 2012. We do not conduct explicit tests of the theory. Rather we identify broad points of empirical alignment and misalignment to suggest what a next round of theory building should include.

\section{Gangs and competitive interactions}

Gang members are well-known for making claims about both their individual competitive prowess and that of their gang (Horowitz and Schwartz 1974; Hughes and Short 2005; Short and Strodtbeck 1965; Densley et al. 2014). How such statements reflect actual competitive dominance on the ground is more difficult to determine. The claims themselves may be inflated, especially if they are perceived to have protective value (Bubolz and
Lee 2018; Lauger 2012; Melde et al. 2009), while objective criteria for what constitutes gang dominance are not obvious.

Here we take a first-principles approach and formally model the impact of competitive dominance from the bottom-up. We start by defining competitive dominance in terms of spatial displacement in dyadic contests. Specifically, in a dyadic contest, the superior competitor is always able to (1) displace an inferior competitor and (2) hold a site in the face of any attempted incursions by an inferior competitor (Tilman 1994). We assume that this absolute displacement ability exists regardless of where and when a dyadic encounter occurs and also that it is unchanged by the situational conditions of interaction. We therefore treat competitive superiority/inferiority as intrinsic characteristics of the gangs being modeled. Our definition of competitive dominance relies on extreme assumptions that are not likely to hold in the real world. However, they do allow us to ask a critical question: What would the world look like if gangs are arranged in a strict competitive hierarchy? To the extent that the realworld is consistent with such expectations, we can say that the mechanisms captured in the model are plausible. Points of inconsistency allow us to reject certain modeling assumptions and revise our expectations.

Here we rely on these modeling assumptions to derive expectations about the size distribution of gangs and the directionality of violence between them. We follow the general approach laid out in Brantingham et al. (2012) in extending ecological models to a consideration of street gangs. Whereas formal ecological models usually consider dynamics in the number or density of individuals in one or more species, we focus on the density of activities assigned to different street gangs. Thus the "size of a gang" here is really a statement about the spatial distribution of gang activities rather than gang members. We develop the models incrementally starting with the simplest case of the activities of a single gang in isolation. We then study two gangs engaged in symmetric and asymmetric competitive interactions. Only then do we turn to the study of a community of gangs arranged in a strict competitive hierarchy. The models are presented in full and then followed by a qualitative examination of empirical evidence.

\section{Modeling competitive dominance Dynamics of a single gang}

Consider a simple model for a single gang in a bounded environment with $s$ different discrete sites in which it might be active. These settings might be street corners (Taniguchi et al. 2011), street segments (Weisburd et al. 2012), police beats (Papachristos 2009), neighborhoods (Grannis 2009), block groups (Tita and Radil 2011) or 
even an arbitrary grid laid out over an urban landscape (Block 2000). Let $p$ be the proportion of sites registering activity by the single gang at any one point in time (see Papachristos 2007). Let $c$ be the rate at which activity spreads to sites in the environment. Let $m$ be the rate at which activity ceases at occupied sites. Given these components we can construct a simple dynamical model describing the rate of change in the number of sites recording gang activity (Nee and May 1992; Tilman 1994):

$$
\frac{d p}{d t}=c p(1-p)-m p .
$$

The interpretation of Eq. (1) is straightforward. The first term on the right-hand side states that the rate of spread of gang activities to different sites is dependent upon the current density of gang activity, captured by the product $c p$. For a fixed rate $c>0$, the proportion of sites occupied increases exponentially in the existing density of activity. However, gang activity can only spread to sites that are currently unoccupied, captured by the term $(1-p)$. If the availability of sites were the only constraint, then gang activity would grow logistically to fill the entire environment. That is, the growth in $p$ slows as the environment fills up, but eventually $p=1$.

Equation (1) goes one step further to assume that gang activity also ceases in locations currently occupied. This is captured by the second term on the right-hand side, $m p$. The rate of activity cessation is also dependent upon the current proportion of sites presenting gang activity. If more sites show gang activity, then more sites will see gang activity cease. Gang activity also grows over time under these conditions, but towards an equilibrium below full saturation of the environment, reflecting a balance between activity spread and cessation. Setting Eq. (1) to zero and solving gives the equilibrium proportion of sites with gang activity (Tilman 1994).

$$
\widehat{p}=1-\frac{m}{c} .
$$

Equation (2) merits brief discussion. Note that if $m \geq c$, then the rate at which gang activity ceases matches or exceeds the rate at which it spreads. This implies $\hat{p}<0$ and ensures that gang activity will never take hold. Gang activity can only persist if $m<c$, meaning that once gang activity has spread to a site it at least has some limited tenure there. The theoretical case of $m=0$ is intriguing (see also Tilman 1994). This implies gang activity never ceases once it is established at a site. This is the only circumstance under which an environment will be completely saturated with gang activity. Infinite persistence of gang activity at a site is theoretically possible if we allow the individuals to seamlessly replace one another over time. However, whether gang activity is considered persistence at a site depends substantially upon the scale of observation (see Mohler et al. 2019; Mohler et al. 2017). We assume that both $c$ and $m$ are intrinsic traits that do not vary through time, but may vary from one gang to another.

\section{Competition among two symmetric gangs}

The single gang model may be extended to consider the dynamics of two gangs with competitive interactions. The first case to consider is competitive interaction between two gangs that are equal, or symmetric in their ability to hold any setting that they currently control. That is, a gang currently active at site $s$ cannot be displaced by a rival that attempts to engage in activity at the site. No competitive hierarchy exists among the gangs.

We now index model parameters for each gang so that $p_{1}$ and $p_{2}$ are the proportion of sites $s$ with activity attributed to gangs 1 and 2, respectively. Similarly, $c_{1}$ and $c_{2}$ reflect the rate of activity spread and $m_{1}$ and $m_{2}$ the rate of activity cessation for gangs 1 and 2, respectively. Putting these together we arrive at:

$$
\begin{aligned}
& \frac{d p_{1}}{d t}=c_{1} p_{1}\left(1-p_{1}-p_{2}\right)-m p_{1}, \\
& \frac{d p_{2}}{d t}=c_{2} p_{2}\left(1-p_{1}-p_{2}\right)-m p_{2} .
\end{aligned}
$$

Equations (3) and (4) are coupled ordinary differential equations describing the rate of change in the proportion of sites occupied by gang 1 and gang 2 , respectively. They are coupled because the proportion of sites with activity attributed to gang 1 constrains the ability of gang 2 to occupy new sites and vice versa. Specifically, the proportion of open sites for new gang activity at any one time is $\left(1-p_{1}-p_{2}\right)$. At equilibrium, the proportions of space taken up by each gang are:

$$
\begin{aligned}
& \widehat{p}_{1}=1-\frac{m_{1}}{c_{1}}-\widehat{p}_{2}, \\
& \widehat{p}_{2}=1-\frac{m_{2}}{c_{2}}-\widehat{p}_{1} .
\end{aligned}
$$

Equations (3) and (4) leads to outcomes similar to those presented in Brantingham et al. (2012). Depending upon the activity spread and cessation rate of each gang, at equilibrium gangs can occupy exactly equal proportions of the environment (Fig. 1a), unequal but stable proportions (Fig. 1b), or one gang can eventually drive the other out of the environment (Fig. 1c). These outcomes are not about a gang's ability to hold space in the face of direct challenges, since both gangs are equal in this regard. 

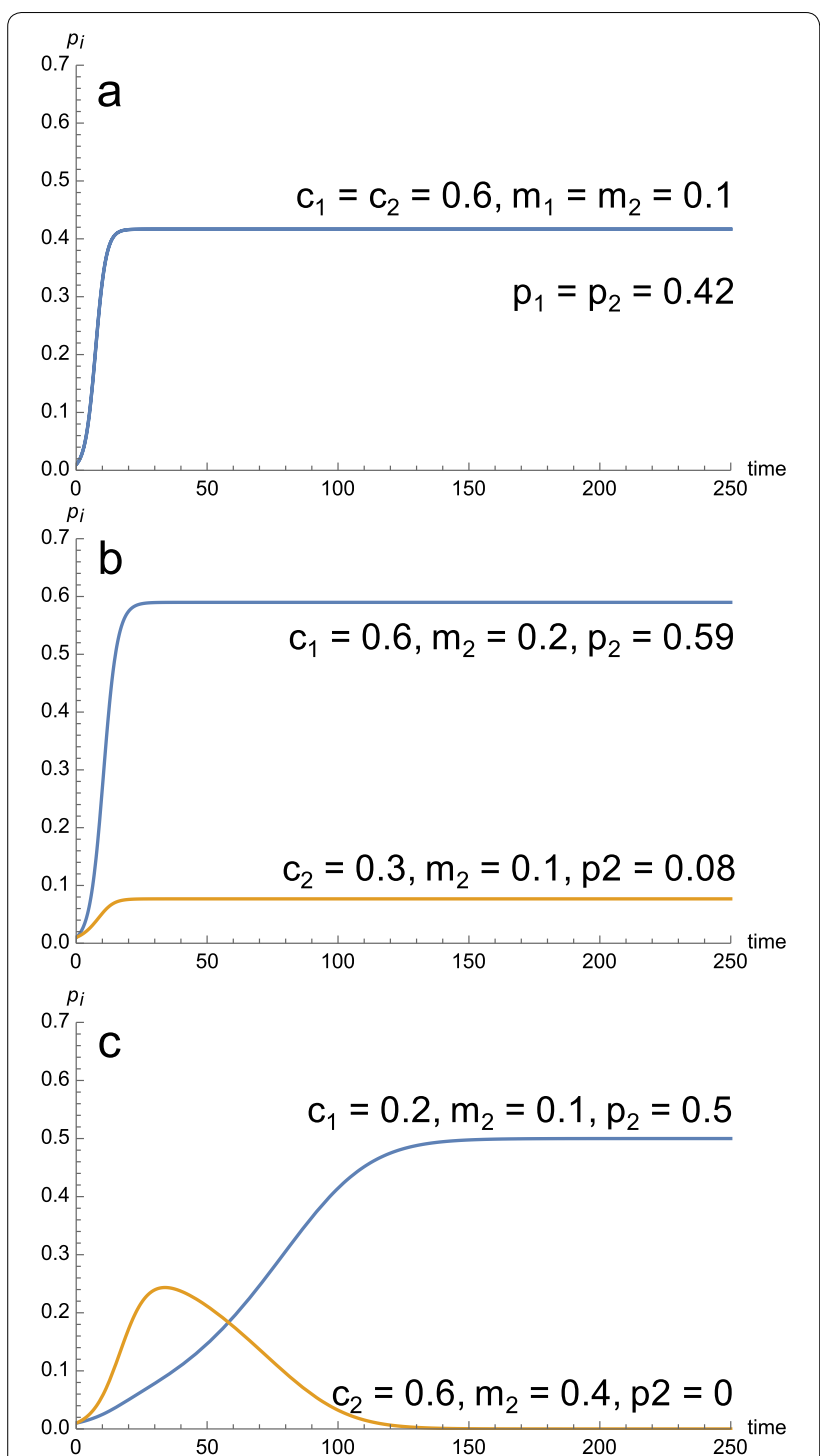

Fig. 1 Dynamics of competition with two gangs with inability to displace their rival. a Two gangs with equal activity spread rates $c=0.6$ and equal activity cessation rates $m=0.1$. The two gangs control equal proportions of the environment at equilibrium $p=0.42$. $\mathbf{b}$ Two gangs with equal inability to displace, but different activity spread and cessation rates. The two gangs control different, but stable proportions of the environment at equilibrium. c Two gangs with equal inability to displace, but different activity spread and cessation rates. In this case, gang 2 is competitively excluded while gang 1 controls exactly $\widehat{p}_{1}=0.5$ of the environment

Rather, the outcomes depend on whether a gang is able to capitalize on vacant space in the environment. Using ecological terminology this would be a case of interference competition. Note then that a non-zero equilibrium density of gang activity $\hat{p}_{i}>0$ for gang $i$ requires $m_{j} / c_{j}<0.5$ for the other gang $j$. Each competitor must leave some space open for its rival if that rival is to persist (Tilman 1994).

\section{Competition among two asymmetric gangs}

The second case to examine is two gangs with asymmetric competitive abilities. Consider a strict competitive hierarchy where gang 1 is always able to displace gang 2 at any site $s$, but gang 2 is never able to displace gang 1 . In the dyadic contest, we call the gang that is always able to displace its rival the superior competitor, while the gang that is never able to displace its rival is the inferior competitor. Referring to them as superior or inferior only denotes their competitive abilities with respect to spatial displacement, not any other attribute of the gangs we might wish to study.

We can write equations governing the dynamics of these two gangs as (Tilman 1994):

$$
\begin{aligned}
& \frac{d p_{1}}{d t}=c_{1} p_{1}\left(1-p_{1}\right)-m_{1} p_{1}, \\
& \frac{d p_{2}}{d t}=c_{2} p_{2}\left(1-p_{1}-p_{2}\right)-m_{2} p_{2}-c_{1} p_{1} p_{2} .
\end{aligned}
$$

Notice several key differences between Eqs. (7) and (8) and their symmetrical counterparts. Equation (7) describes the rate of change in the proportion of sites with activity attributed to gang 1 . It is not coupled to the dynamics of gang 2, meaning that whatever the dynamics of gang 2 might be, it does not influence the dynamics of gang 1 . This is a direct consequence of the strict competitive hierarchy. The equilibrium proportion of sites with gang 1 is actually no different than what would be the case if it were alone in the environment.

Equation (8) reflects quite different dynamics. The dynamics of gang 2 are coupled to the dynamics of gang 1 . The term $\left(1-p_{1}-p_{2}\right)$ suggests that the rate of spread of gang 2 activities is limited to those sites currently left open by gang 2 and gang 1 . This is analogous to the symmetrical case given in Eq. (4). The strict competitive hierarchy introduces another point of coupling, however. The term $c_{1} p_{1} p_{2}$ captures the impact of competitive displacement events, where gang 1 encounters and competitively excludes gang 2 . In probabilistic terms, $c_{1} p_{1}$ is the probability that gang 1 spreads to a site and $p_{2}$ is the probability that the site already hosts gang 2 .

It is reasonable to suppose that the ecological conditions modeled by Eqs. (7) and (8) do not favor the persistence of gang 2. However, Tilman (1994) demonstrated that the inferior competitor can persist if it is able to take advantage of the sites left unoccupied by the superior competitor (see also Nee and May 1992). At equilibrium, 

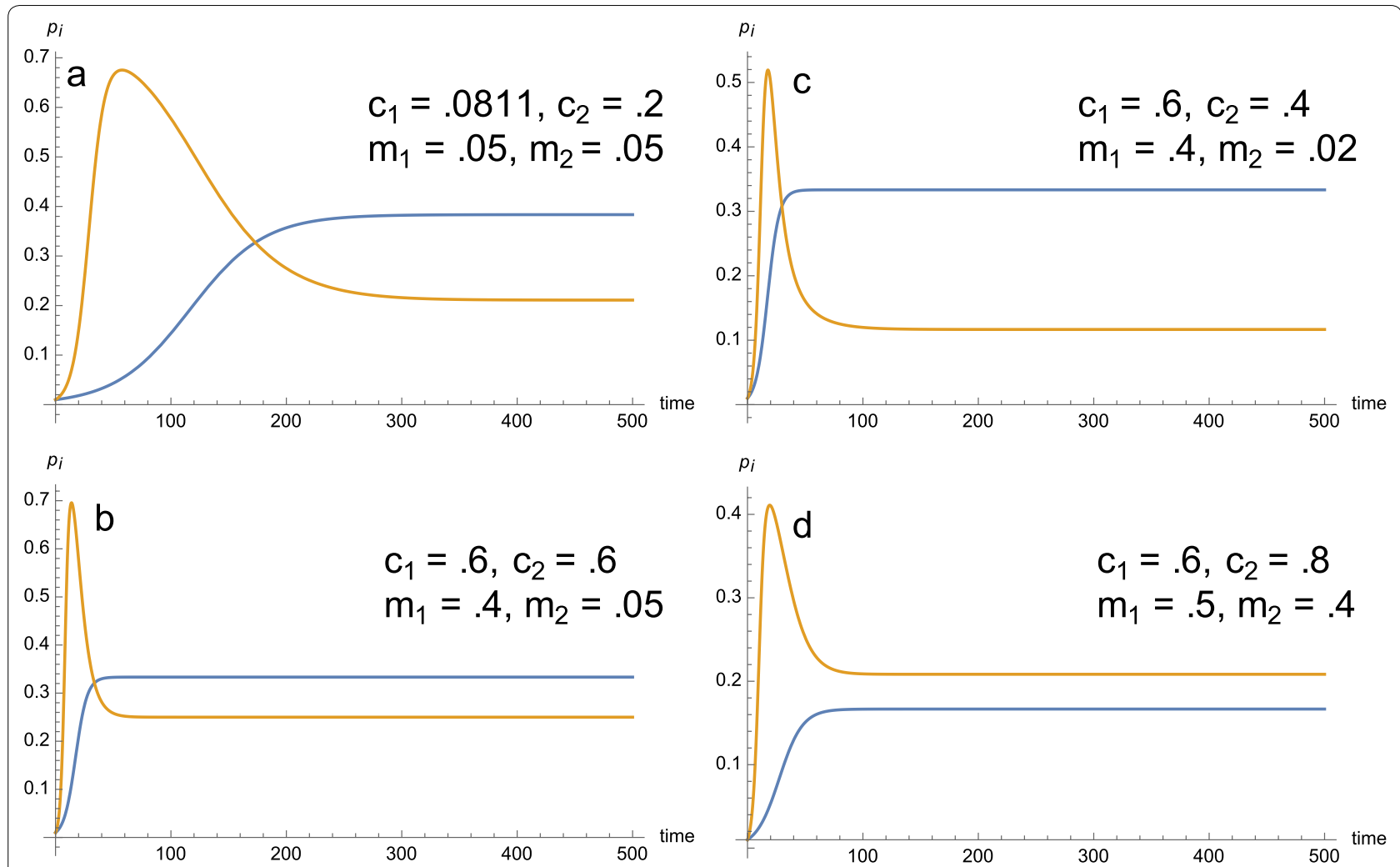

Fig. 2 Abundances of competitively superior (blue) and inferior (orange) gangs over time given different activity spread and cessation rates. a The inferior gang has a higher activity spread rate than the superior gang. $\mathbf{b}$ The inferior gang has a lower cessation rate than the superior gang. $\mathbf{c}$ The inferior gang has a lower activity spread rate and lower activity cessation rate than the superior gang. $\mathbf{d}$ The inferior competitor has a higher activity spread rate and lower activity cessation rate than the superior competitor

there will be $\left(1-\widehat{p}_{1}\right)$ sites left open by the superior competitor at any one time. The inferior competitor must be able to find and exploit those sites before they are displaced completely.

There are two distinct ways in which open sites can be exploited by inferior competitors. The inferior competitor can persist if its rate of activity spread exceeds that of the superior competitor. Specifically, if

$$
c_{2}>c_{1}\left(\frac{\widehat{p}_{1}}{1-\widehat{p}_{1}}+\frac{m_{2}}{m_{1}}\right)
$$

then the inferior gang will be able to invade the environment and maintain activity over some equilibrium proportion of sites. If we assume that the superior and inferior gangs have the same activity cessation rate $m_{1}=m_{2}=m$, then Eq. (9) simplifies to (Tilman 1994):

$$
c_{2}>c_{1}\left(\frac{1}{1-\widehat{p}_{1}}\right) \text {. }
$$

Equation (10) is revealing. As the equilibrium proportion of sites occupied by the superior gang declines towards zero (i.e., $\widehat{p}_{1} \rightarrow 0$ ), the minimum spread rate needed to sustain the inferior gang approaches that of the superior one. Conversely, as the environment fills up with activity by the superior gang, the spread rate for the inferior gang must increase nonlinearly to ensure persistence. For example, when the superior gang is present in a proportion $\widehat{p}_{1}=0.25$ of sites given an activity spread rate of $c_{1}=0.2$, the inferior gang must have an activity spread rate of at least $c_{2}>0.2667$ to be able to persist, assuming equal activity cessation rates $m$. The inferior gang must maintain at least a $33 \%$ faster activity spread rate. When the superior gang is present in a proportion $\widehat{p}_{1}=0.75$ of sites, given an activity spread rate of $c_{1}=0.2$, the inferior gang must have an activity spread rate of at least $c_{2}>0.8$. In this case, the inferior gang must spread at least $300 \%$ faster than the superior gang to capitalize on open space. In general, the greater the proportion of space occupied by a superior gang at equilibrium, the faster the inferior gang needs to spread to ensure survival.

The consequences of a faster rate of activity spread are shown in (Fig. 2a). Starting at low initial abundances, the inferior gang rapidly increases its presence, peaking at 
$p_{2}=0.675$ after about 57 time-steps. The higher activity spread rate allows it to capitalize on all of the empty space initially present. The inferior gang then starts to lose ground as the superior gang occupies more and more space. This reflects both the superior gang displacing the inferior gang and the superior gang preempting the inferior gang at some sites. Eventually, the superior gang surpasses the inferior gang in the proportion of sites occupied, which happens around 173 time-steps into the simulation. At equilibrium, the superior gang holds a proportion $\widehat{p}_{1}=0.38$ of the sites and the inferior gang a proportion $\widehat{p}_{2}=0.21$ of the sites. The inferior competitor survives in spite of the absolute competitive superiority they face at each site.

The competitively inferior gang may also persist if it maintains a lower activity cessation rate relative to the superior gang. However, this strategy is more limited. Rearranging Eq. (9) to solve for $m_{2}$, and assuming that the two gangs have the same activity spread rate $c_{1}=c_{2}=c$, yields (Tilman 1994):

$$
m_{2}<m_{1}\left(1-\frac{\widehat{p}_{1}}{1-\widehat{p}_{1}}\right) .
$$

The inferior gang can persist only if it ceases activities at a rate slower than the superior gang. The activity cessation rate for the inferior gang can be very close to that of the superior gang when the superior gang occupies very few sites at equilibrium (i.e., when $\widehat{p}_{1} \approx 0$ ). However, the activity cessation rate for the inferior gang must quickly approach zero as the equilibrium proportion of sites occupied by the superior gang approaches $\hat{p}_{1}=0.5$. As the superior gang increases its hold on space, the inferior gang is put under more displacement pressure and therefore must hold on to any sites that it does occupy for as long as it can. If the superior gang occupies more than a proportion $\hat{p}_{1}>0.5$ of sites at equilibrium, the inferior gang cannot rely on reducing activity cessation rates to persist (Tilman 1994). To see why, notice that the term $\widehat{p}_{1} /\left(1-\widehat{p}_{1}\right)$ in Eq. (11) is analogous to the odds that any given site is occupied by the superior gang. The odds are greater than 1 when $\hat{p}_{1}>0.5$, meaning that the inferior gang cannot be guaranteed to find any open space.

Persistence of the inferior gang as a result of lower activity cessation rates is illustrated in Fig. $2 \mathrm{~b}$. Here the two gangs have the same rate of activity spread, but different rates of activity cessation. Qualitatively the trajectory towards equilibrium looks similar to the case of differential activity spread rates, even though the mechanism is very different. Starting at the same low initial abundances, the inferior gang early on comes to occupy a large fraction of the environment, holding approximately $p_{2}=0.70$ of the sites only 14 time steps into the simulation. Eventually, however, the superior competitor occupies a sufficient proportion of sites that it starts to competitively exclude the inferior competitor, driving down its abundance. At equilibrium, the superior competitor occupies a proportion $\widehat{p}_{1}=0.33$ of the site, while the inferior competitor occupies a proportion $\widehat{p}_{2}=0.25$ of sites.

The outcomes shown Fig. 2a and b are not the only ones possible. The inferior gang can be driven to extinction under a wide range of conditions (not shown). It is also possible for the inferior gang to persist with a lower activity spread rate than the superior gang as long as it has an activity cessation rate sufficiently below that of its competitor (Fig. 2c). It is also possible for the inferior gang to exist at a greater abundance than the superior gang. This seems counter intuitive, but is possible if the inferior gang has an activity spread rate that is higher than the superior competitor and an activity cessation rate that is lower than the superior competitor. Such a case is shown in Fig. 2d. Here the equilibrium proportion of the inferior competitor is $\widehat{p}_{2}=0.21$, while the proportion of the superior competitor is $\widehat{p}_{1}=0.17$.

\section{Competition in a community of asymmetric gangs}

Tilman (1994) illustrates how the two gang model can be extended to a community of street gangs. We start with the same environment consisting of $s$ different discrete sites or settings in which gangs might be active. There is community of $n$ total gangs present in the environment and they can be ranked into a strict competitive hierarchy $i=1,2, \ldots, n$. The most competitive gang is positioned at the top $(i=1)$ and the least competitive gang at the bottom $(i=1)$ of the hierarchy. ${ }^{1}$ Gangs positioned higher in the hierarchy can displace all gangs lower in the hierarchy. Conversely, gangs positioned lower in the hierarchy are never able to displace gangs higher up. This is a strict "pecking order" consistent with the analyses in Papachristos (2009) and Randle and Bichler (2017).

To model the dynamics of this competitive hierarchy, let $p_{i}$ be the proportion of sites registering activity by the gang $i$. Let $c_{i}$ be the rate at which gang $i$ 's activity spreads to other sites in the environment. Let $m_{i}$ represent the rate at which gang $i$ 's activity ceases at sites with activity. The change in the fraction of sites occupied by gang $i$ (Tilman 1994) is:

$$
\frac{d p_{i}}{d t}=c_{i} p_{i}\left(1-p_{i}-\sum_{j=1}^{i-1} p_{j}\right)-m_{i} p_{i}-\sum_{j=1}^{i-1} c_{j} p_{j} p_{i} .
$$

\footnotetext{
${ }^{1}$ Below we will also index gangs using $k=1,2, \ldots, n$ in decreasing order of the equilibrium proportion of space occupied, independent of where they fall in the competitive hierarchy $i=1,2, \ldots, n$.
} 
The term in Eq. (12) states that gang $i$ cannot spread to any site that is currently held by any gang higher in the competitive hierarchy. That is, the available space is reduce by sites held by the highest ranked gang $j=1$, the second highest ranked gang $j=2$, and so on, through to the sites held by gang $j=i-1$, the gang immediately above $i$ in the hierarchy. Gang $i$ also interferes with its own spread. Gang $i$ ceases activity at a rate $m_{i} p_{i}$, a density dependent effect. Gang $i$ is also displaced by all higher ranked gangs. This can be seen in the second summation, which takes into account the spread of the highest ranked gang $j=1$, the second highest ranked gang $j=2$, and so on, through to gang $j=i-1$, the gang immediately superior to gang $i$. Setting Eq. (12) to zero and solving for $p_{i}$ gives the equilibrium frequency of gang $i$ within the strict competitive hierarchy (Tilman 1994):

$$
\widehat{p}_{i}=1-\frac{m_{i}}{c_{i}}-\sum_{j=1}^{i-1} \widehat{p}_{j}\left(1+\frac{c_{j}}{c_{i}}\right) .
$$

The first two terms on the right-hand side of Eq. 13 together reflect the how the activities of gang $i$ influence its own equilibrium proportion, independent of competitive effects. As in the two-gang case, gang $i$ can only hold territory if $m_{i}<c_{i}$. The second term on the righthand side reflects the additional impact of competitive displacement by higher-ranked gangs. In general, the equilibrium proportion of gang $i$ is reduced by the total proportion of space occupied by superior gangs, scaled by the ratio of activity spread rates for each superior gang relative to gang $i$.

The conditions under which any inferior gang $i$ can survive in the face of competition from any number of superior gangs can be established by solving Eq. (13) for $\widehat{p}_{i}>0$ and isolating either $c_{i}$ or $m_{i}$. The mathematical results are conceptually the same as for the two-gang asymmetrical case so we do not detail them here (see Tilman 1994, p. 7). In general, a gang $i$ must have an activity spread rate $c_{i}$ that is faster than that of the next higher ranked gang $c_{i-1}$, scaled by the proportion of sites left open by higher ranked gangs. Alternatively, the activity cessation rate for gang $i$ must be less than the cessation rate for the immediately superior gang $i-1$ scaled by the proportion of sites left open by superior gangs. Inferior competitors up and down the hierarchy can also mix different activity spread and cessation rates to ensure survival.

Equation (12) leads to a range of outcomes (Fig. 3). Gangs may occupy space in proportions that are positively rank-order correlated with their competitive abilities, although this outcome can result from different mechanisms. In Fig. 3a, for example, gangs ranked 1-4 in the competitive hierarchy achieve equilibrium proportions $\widehat{p}_{i}=\{0.2,0.16,0.08,0.05\}$, respectively, as a result
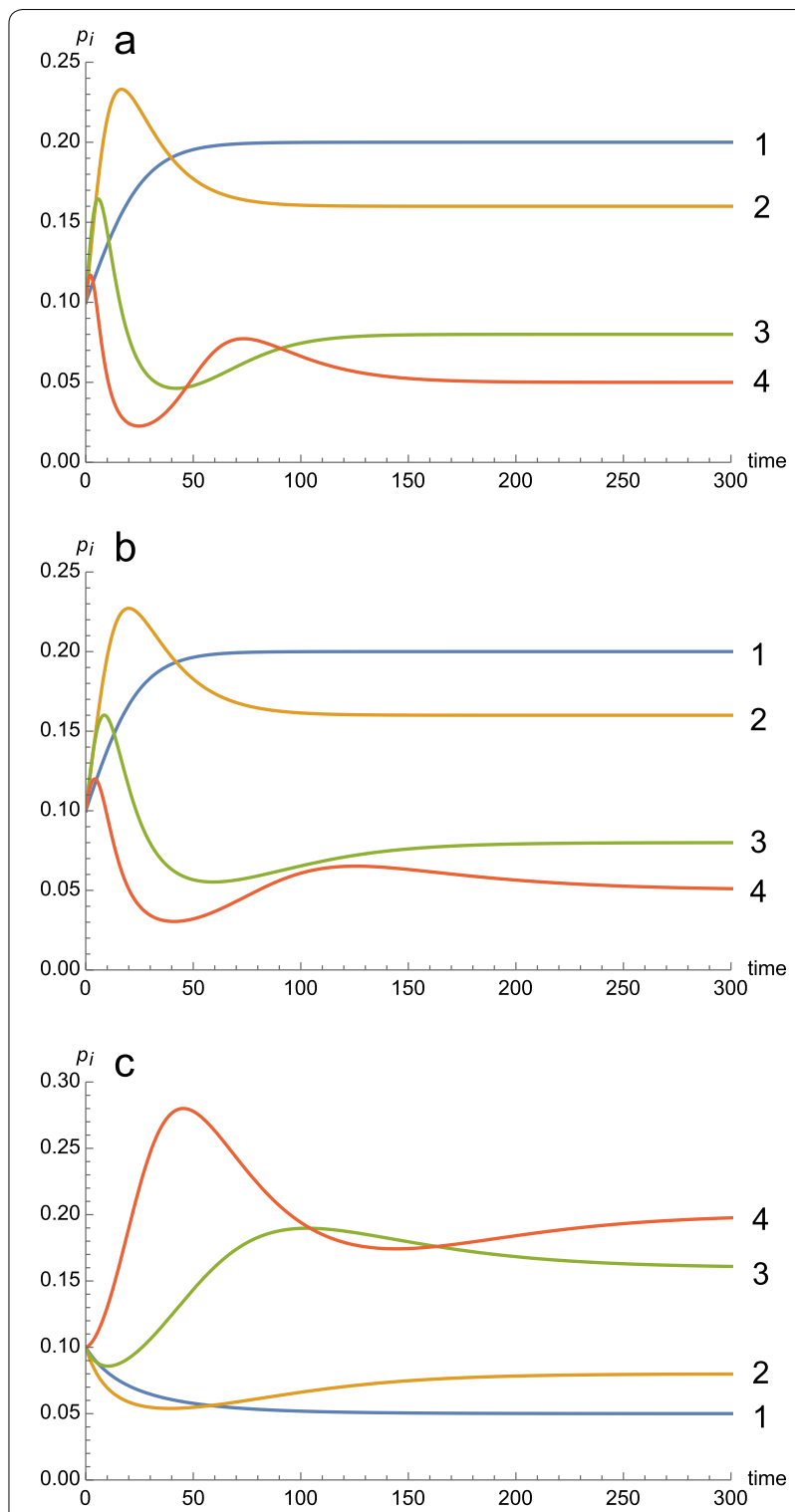

Fig. 3 Dynamics of four competing gangs with a strict competitive hierarchy. $\mathbf{a}$ Gangs have equal activity spread rates $c=0.4$, but different activity cessation rates $m=\{0.421,0.176,0.08,0.028\}$. $\mathbf{b}$ Gangs have equal activity cessation rates $m=0.3$, but different activity spread rates $c=\{0.375,0.586,0.837,1.05\}$. c Gangs show a mixture of activity spread and cessation rates $c=\{0.526,0.375,0.22$, $0.278\}$ and $m=\{0.5,0.3,0.1,0.05\}$. The abundance of gang activity at equilibrium need not reflect gang ability to displace. However, it remains the case that any competitively inferior gang must maintain a higher activity spread rate and/or lower activity cessation rate than their immediate superior to be able to persist

of differing activity spread rates. In Fig. 3b, they occupy exactly the same proportions of space at equilibrium, but this time because of differing activity cessation rates. Most importantly, gangs may occupy space in proportions that do not at all track their relative competitive 
abilities. In Fig. 3c, for example, gangs ranked 1-4 in the competitive hierarchy occupy proportions $\widehat{p}_{i}=\{0.05,0.08,0.16,0.2\}$, respectively, a perfect inversion of the actual competitive ranking. This is achieved by gangs deploying a mixture of activity spread and cessation rates. The key observation is that the proportion of space occupied by a gang (i.e., territory size) is alone not sufficient to infer competitive dominance.

\section{Violence in a community of gangs}

It this section we extend Tilman's (1994) original model to help characterize patterns of violence between rival gangs. The hope is that patterns of violence may be a more faithful proxy of competitive ability since it is more directly related to between-gang interactions. There are two fundamental types of violence that might occur between rivals structured in a strict competitive hierarchy. The first arises from instances where a competitively superior gang encounters and successfully displaces a competitively inferior gang. This can be described as "top-down" violence since the competitive exchange is initiated by the superior competitor. The second arises from instances where an inferior gang attempts (but fails) to displace a superior gang. This can be described as "bottom-up" violence since the competitive exchange is initiated by the inferior competitor.

Focusing on the simplest case of an environment with only one superior and one inferior gang, labeled as gang 1 and gang 2, respectively, the fraction of sites at which top-down interactions occur at equilibrium is $c_{1} \widehat{p}_{1} \widehat{p}_{2}$. This is simply the third term in Eq. (8), substituting the equilibrium frequencies for gangs 1 and 2 . While $c_{1} \widehat{p}_{1} \widehat{p}_{2}$ describes the top-down displacement rate, we expect only a fraction of those encounters will escalate to fullblown violence (Decker 1996). We propose therefore that the actual frequency of top-down violence is only proportional to $c_{1} \widehat{p}_{1} \widehat{p}_{2}$. Similarly, the proportion of sites where an inferior competitor attempts (but fails) to take control of a site already occupied by a superior competitor is given by $c_{2} \widehat{p}_{1} \hat{p}_{2}$, for a system with only two gangs. This is found by expanding the first term Eq. (8). Here as well we assume that the actual frequency of bottom-up violence is only proportional to $c_{2} \widehat{p}_{1} \widehat{p}_{2}$.

There are three basic patterns of top-down and bottom-up violence over time (Fig. 4). When activity cessation rates are the same, necessitating faster activity spread rates for inferior competitors to persist, bottomup violence occurs at a greater frequency than topdown violence (Fig. 4a). When activity spread rates are the same, necessitating differences in activity cessation rates for inferior competitors to persist, top-down and bottom-up violence occur in equal proportions (Fig. 4b). Equilibrium conditions that mix different activity spread

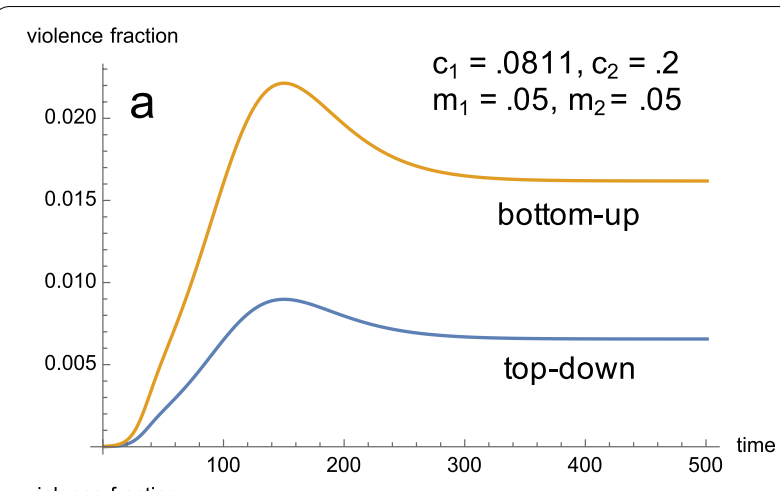

violence fraction

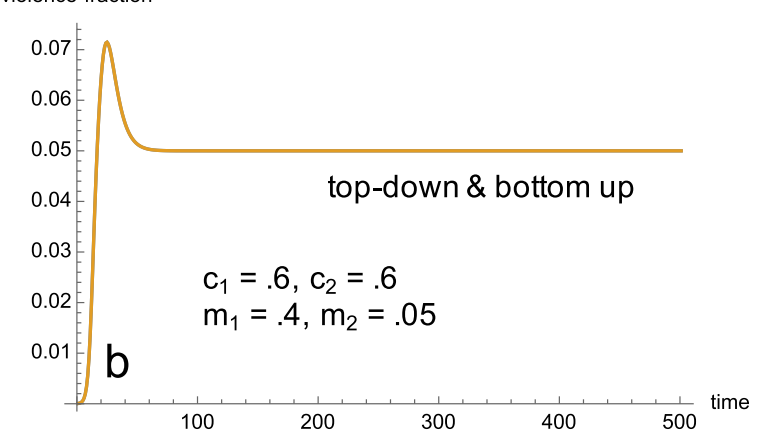

violence fraction

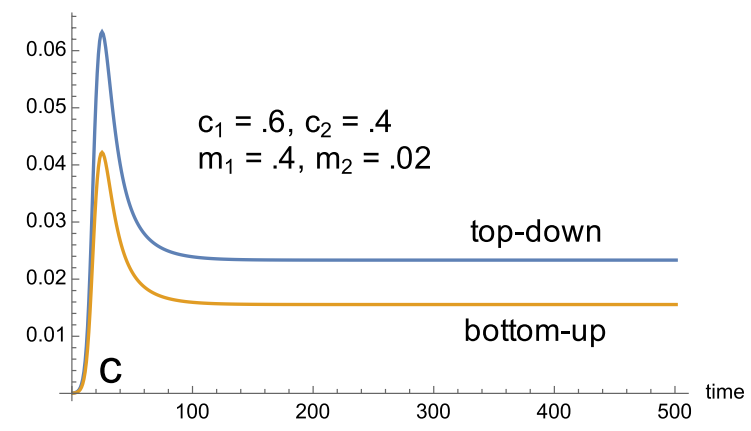

Fig. 4 The proportion of activities with hypothesized "top-down" and "bottom-up" violence. a The inferior gang is numerically less abundant at equilibrium, but persists through a higher activity spread rate (see Fig. 2a). The inferior gang is also subject to a greater proportion of "top-down" violence. $\mathbf{b}$ The inferior gang is numerically less abundant, but persists through a lower activity cessation rate (see Fig. 2b). The amount of "top-down" violence equals the amount of "bottom-up" violence. c The inferior gang is numerically less abundant, which is achieved through a lower activity spread rate and lower activity cessation rate (see Fig. 2c). In this case, "bottom-up" violence exceeds "top-down" violence

and cessation rates can produce patterns consistent with the two prior cases, but also situations where top-down violence exceeds bottom-up violence (Fig. 4c). The key observation is that the frequency of violence between rival gangs is alone not sufficient to infer competitive ranking of those gangs.

We therefore take a step back from the question whether violence is top-down or bottom-up and look 

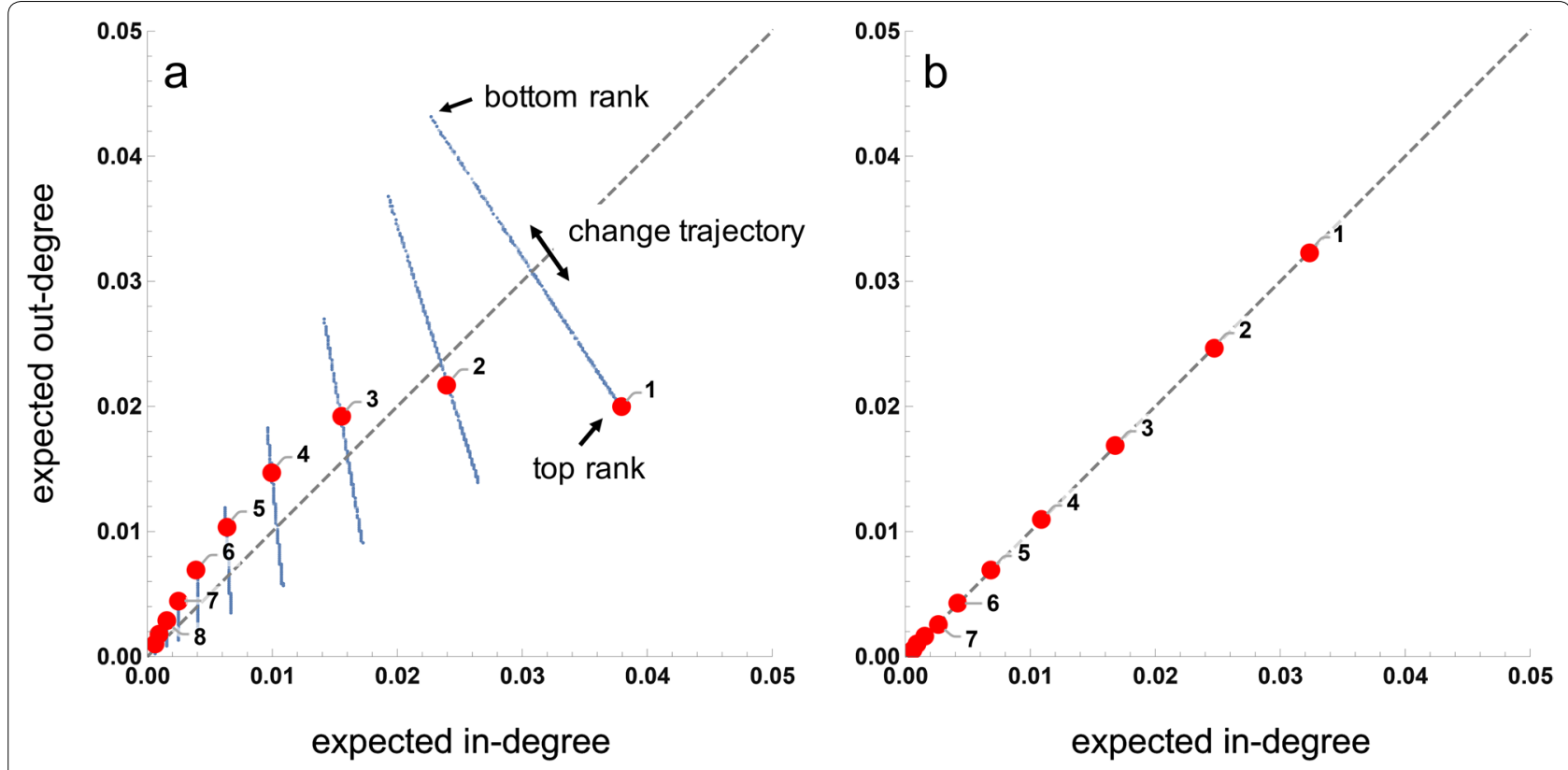

Fig. 5 The expected in- and out-degree for ten gangs arranged in a competitive hierarchy. Gangs located below the diagonal are net importers of violence. Gangs located above the diagonal are net exporters of violence. Red points are for gangs where the equilibrium territory proportion decreases with decreasing rank. Blue points form a trajectory along which a gang's in- and out-degree changes as rank in the competitive hierarchy changes. a Inferior gangs persist because of higher activity spread rates. $\mathbf{b}$ Inferior gangs persist because of lower activity cessation rates. Trajectories are generated in via simulations that randomly assign gangs to different rank positions

only at the direction of violence between the aggressor and the targeted gangs. In a network context, an outbound edge is drawn anytime an aggressor gang seeks to spread into an area that is already occupied, whether or not displacement is successful. An inbound edge is drawn to any gang that is the target of displacement, successful or not. At equilibrium, the sum of all outbound edges is the out-degree of a gang. The sum of all inbound edges at equilibrium is the in-degree of the gang. In formal terms, the in- and out degree for gang $j$ at equilibrium are given as:

$$
\begin{aligned}
& \underbrace{\widehat{p}_{j} \sum_{i \neq j} c_{i} \widehat{p}_{i}}_{j \text { 's in-degree }}=\underbrace{\widehat{p}_{j} \sum_{i=1}^{j-1} c_{i} \widehat{p}_{i}}_{i \text { to } j \text { top-down }}+\underbrace{\widehat{p}_{j} \sum_{i=j+1}^{n} c_{i} \widehat{p}_{i}}_{i \text { to } j \text { bottom-up }} \\
& \underbrace{c_{j} \widehat{p}_{j} \sum_{i \neq j} \widehat{p}_{i}}_{j \text { 's out-degree }}=\underbrace{c_{j} \widehat{p}_{j} \sum_{i=1}^{j-1} \widehat{p}_{i}}_{j \text { to } i \text { bottom-up }}+\underbrace{c_{j} \widehat{p}_{j} \sum_{i=j+1}^{n} \widehat{p}_{i}}_{j \text { to } i \text { top-down }} .
\end{aligned}
$$

Index $j$ identifies the focal gang, while rivals both higher and lower in the competitive hierarchy are labeled by index $i$. Note that Eqs. (14) and (15) exclude selfloops. If the in- and out-degree are equal, then gang $j$ has a balanced violence profile with respect to rivals (see Papachristos 2009). If the in-degree exceeds the outdegree, gang $j$ is a net importer of violence. If the outdegree exceeds the in-degree, gang $j$ is a net exporter of violence. It is important to note that Eqs. (14) and (15) translate displacement rates into edges in a network. Since displacement rates are not whole numbers, while in- and out-degrees are necessarily so, we can think of the output of Eqs. (14) and (15) as generating expected values of the degree distributions.

Figure 5 shows the expected in- and out-degree at equilibrium for a community of ten gangs with equilibrium territory proportions given by the formula $\hat{p}_{k}=0.31 * e^{-0.5 k}$, where $k$ is a label tied to a gang's equilibrium proportion, independent of its order in the competitive hierarchy. The red points in Fig. 5 correspond to a baseline case where the equilibrium territory proportions decrease in rank order with competitive ability (i.e., $k=i$ ). Thus, the gang at the top of the hierarchy (rank $i=1$ ) has the largest equilibrium territory proportion $(k=1)$, the gang in the second position $(\operatorname{rank} i=2)$ has the second largest equilibrium territory proportion $(k=2)$, and so on (see Fig. 3a). Figure 5 is meant to be comparable to Papachristos (2009, p. Figure 2). The red points are obtained by explicitly solving Eq. (12) for chosen values of $c_{i}$ or $m_{i}$ at equilibrium. The blue points transecting the one-to-one line in Fig. 5a correspond to 
alterative orderings of the competitive hierarchy (i.e., where $k$ and $i$ may be in different orders) (see below).

Figure $5 \mathrm{a}$ shows the case for competing gangs with equal activity cessation rates $m_{i}=m=0.3$. Inferior gangs therefore must have faster activity spread rates to achieve the specified equilibrium territory proportion $\widehat{p}_{k}$. Focusing first on the red points, save for the two gangs at the top of the competitive hierarchy, who are net importers of violence (i.e., in-degree> out-degree), all other lower ranked gangs are net exporters of violence (i.e., out-degree $>$ in-degree). The faster spread rates for lower ranked gangs drive interactions in areas already occupied by rivals, leading to a net exporting of violence by these lower ranked gangs. Note that the gangs in the middle of the hierarchy display the greatest imbalance between inand out-degree. Farther down the competitive hierarchy, gangs approach a balance between in- and out-degree. In the middle of the competitive hierarchy faster spread rates combine with intermediate turf sizes to produce a large net exporting of violence. Farther down the hierarchy, faster spread rates cannot overcome smaller turf sizes, leading to a greater balance between importing and exporting violence. In other words, the tendency for faster spread rates to export more violence is overridden by density dependent effects for gangs at the bottom of the competitive hierarchy.

Figure 5a also illustrates what happens if we relax the baseline assumption that equilibrium territory proportions must track competitive ability. This relaxation is a theoretical possibility suggested by Fig. 3c. For example, the gang with the largest equilibrium territory proportion $(k=1)$ may appear at the top $(i=1)$ or bottom $(i=10)$ of the competitive hierarchy. A key mathematical challenge is that there are $10 !=3.6288 \times 10^{6}$ unique competitive hierarchies for this hypothetical community of ten gangs. We therefore use simulation to generate ten-thousand communities with the position of each gang in the competitive hierarchy assigned randomly in each iteration. Even though this is a small fraction of the total possible number of unique hierarchies there appears to be little qualitative difference in the results between simulations with 100 and 10,000 iterations. There is a distinctive pattern of interaction between equilibrium territorial proportion $\widehat{p}_{k}$ and competitive rank $i$ for the case of fixed activity cessation rates $m_{i}=m=0.3$ and variable activity spread rates $c_{i}$ (Fig. 5a). Change in a gang's rank position from the top to the bottom of the competitive hierarchy drives a shift in that gang from being a net importer of violence (i.e., in-degree > out-degree) to a net exporter (i.e., in-degree< out-degree). For example, the gang with the largest equilibrium territorial proportion (labeled $k=1$ ) is maximally imbalanced towards net importation of violence when it is at the top of the competitive hierarchy. It is maximally imbalanced towards net exportation of violence when it is at the bottom of the competitive hierarchy. The transition follows a linear path that transects the one-to-one line. In this particular case, the gang with the largest territory is a net exporter of violence whenever it occupies a rank of seven or lower $(i \geq 7)$ in the competitive hierarchy. The gang with the second largest equilibrium proportion $(k=2)$ occupies a position away from the two extremes when it is ranked second $(i=2)$ in the competitive hierarchy (red point). With this competitive rank the gang is a net importer of violence. It imports more violence when it occupies the top position in the competitive hierarchy $(i=1)$. It becomes a net exporter of violence when it drops down the competitive hierarchy. In general, each gang can swing from being a net importer of violence to a net exporter of violence with changes in its own rank position. However, there are also complex interactions between gangs that impact the directionality of violence. For example, shifting the top two gangs by size ( $k=1$ and $k=2)$ from the top two rank positions $(i=1$ and $i=2)$ to the bottom two rank positions $(i=10$ and $i=9)$ not only drives these gangs to be net exporters of violence, but it also forces all of the other gangs to be net importers of violence. Fully exploring such interactions is beyond the scope of the present paper.

Figure 5b shows two similar scenarios starting with the assumption that the ten gangs have equal activity spread rates $c_{i}=c=0.6$. Under these conditions, the only way for inferior gangs to persist is to deploy lower activity cessation rates. As in Fig. 5a the red points correspond to the baseline case where the equilibrium territory proportions are rank-order correlated with position in the competitive hierarchy. Unlike the case with equal activity cessation rates, all gangs line up in sequence along the diagonal. Each gang is perfectly balanced in the proportion of violence it imports and exports, though gangs with the larger equilibrium territory proportions experience higher rates of violence overall. This result was anticipated by Fig. 4b. Differences between gangs in activity cessation rates have no impact on the directionality of violence. What is surprising perhaps is that change in the rank order position of gangs in the competitive hierarchy does not affect the balance of violence (Fig. 5b). In ten-thousand simulations with random ordering of the competitive hierarchy, gangs remain perfectly balanced in their in- and out-degree and unchanged in the sequential order. The key observation from both of the simulations above is that equilibrium territory proportion, particularly the ordering from large to small, in conjunction with imbalances in the directionality of violence can sometimes be informative of differences in competitive rank. 


\section{Primary theoretical observations}

The mathematical models of competition in a community of gangs introduced above produce four main theoretical insights. First, closely following Tilman's (1994) original conclusions, inferior gangs that are displaced in any dyadic contest by a superior gang, should be able to persist if they can quickly find and exploit open space in the environment. Second, because the ability to find and exploit open space can be achieved through a mixture of higher activity spread rates and lower activity cessation rates, it is possible for inferior gangs to exist at larger equilibrium sizes than their superior competitors. In other words, territory size alone is not necessarily a reliable proxy of competitive dominance. Third, variability in activity spread rates is a primary driver of imbalances in the directionality of gang violence. Variability in activity cessation rates has no impact on the directionality of violence. Finally, variability in the rank position of a gang in the competitive hierarchy can drive a gang from being a net importer of violence to being a net exporter of violence. Net importation of violence (high in-degree) occurs when a gang is ranked closer to the top of the competitive hierarchy, while net exportation of violence (high out-degree) occurs when a gang is ranked closer to the bottom of the competitive hierarchy. However, the rank of one gang in the competitive hierarchy can have an impact on the balance of violence among other gangs.

\section{Gang size and violence in Hollenbeck}

We now turn our attention to an empirical case study to further explore the theoretical observations developed above. The case study is focused on the Hollenbeck Community Policing Area of the Los Angeles Police Department (LAPD), located on the eastern edge of the City of Los Angeles (Fig. 6). As of 2010, Hollenbeck has a resident population of approximately 186,960 people living in a 15.2 sq. mile area $\left(39.4 \mathrm{~km}^{2}\right)$. A quarter of the residents live below the poverty line $(25.2 \%)$ and about a third live in owner-occupied residences (30.5\%). The majority population is Hispanic (84.1\%), with most individuals tracing their ancestry to Mexico (Manson et al. 2018).

Hollenbeck has a well-documented chronic gang problem stretching back over 70 years (Gustafson 1940; Valasik 2014). The overwhelming impression is a stable representation of gangs in the area (Valasik et al. 2017). As many as 40 gangs were identified in Hollenbeck as of 1951 (Ranker 1957), including different age-based sets of the same gang. Many of the same gangs are still present on the street more than 50 years later. Tita et al. (2004) identified 29 street gangs active in Hollenbeck in the late 1990s and early 2000s. More recent estimates identify 31 gangs (see Brantingham et al. 2012; Valasik et al. 2017). Thirteen of these gangs present in recent surveys are tied to the Lincoln Heights, Montecito Heights and El Sereno neighborhoods, North of the 10 Freeway. The remaining 18 gangs are tied to the Boyle Heights neighborhood, South of the 10 Freeway. The gangs of Hollenbeck are of dramatically different sizes (Table 1). For example, using LAPD gang maps compiled in 2010, the territory size attributed to El Sereno is two orders of magnitude larger than the turf attributed to the Clarence Street. Additionally, the largest gang by estimated number of gang members is an order of magnitude larger than the smallest gang. Hollenbeck may provide excellent example of gangs persisting in the face of competitive pressure.

\section{Empirical challenges}

It is premature to conduct a rigorous statistical test of model predictions given a number of outstanding empirical challenges. We seek only to identify broad points of alignment/misalignment between theory and data to reveal potential next steps in modeling. The least problematic point of articulation between theory and data is with the equilibrium proportion of space occupied by a gang $i$ (but see below). The parameter $\widehat{p}_{i}$ may be estimated either directly from turf maps, or indirectly via a census of gang members. The stability of named gangs in Hollenbeck over a long period of time suggests that both measures are in equilibrium; or at least as close as you could ever hope to get in a real-world setting. We use turf size as our preferred estimate. Note that the estimates in Table 1 are computed as the territory size divided by the total land area of Hollenbeck (15.2 sq. miles). Therefore, the sum of equilibrium proportions is less than one (i.e., $\left.\sum \widehat{p}_{i}<1\right)$.

There is no easy way at this point to empirically measure the rate of activity spread $c_{i}$, or rate of activity cessation $m_{i}$ for gangs. It is similarly difficult to measure the absolute competitive ability of gangs. In theory, each of these quantities could be estimated from field-based social observations (e.g., Weisburd et al. 2006). The rate of activity spread could be estimated from the fraction of street segments that transition from no recorded activity by gang $i$ to some recorded activity by gang $i$ during an observational period of time. Similarly, the rate of activity cessation could be estimated from the fraction of street segments that transition from having activity by gang $i$ to no activity by gang $i$, but only where activity cessation was not the result of active displacement. Field interview cards, which record non-crime interactions between police and the public, could be used to make such inferences, if the sampling frame for field interviews was well-understood (Faust and Tita 2009; Papachristos et al. 2015; Valasik and Tita 2018; van Gennip et al. 2013). We do not seek to directly estimate activity spread or cessation rates. 


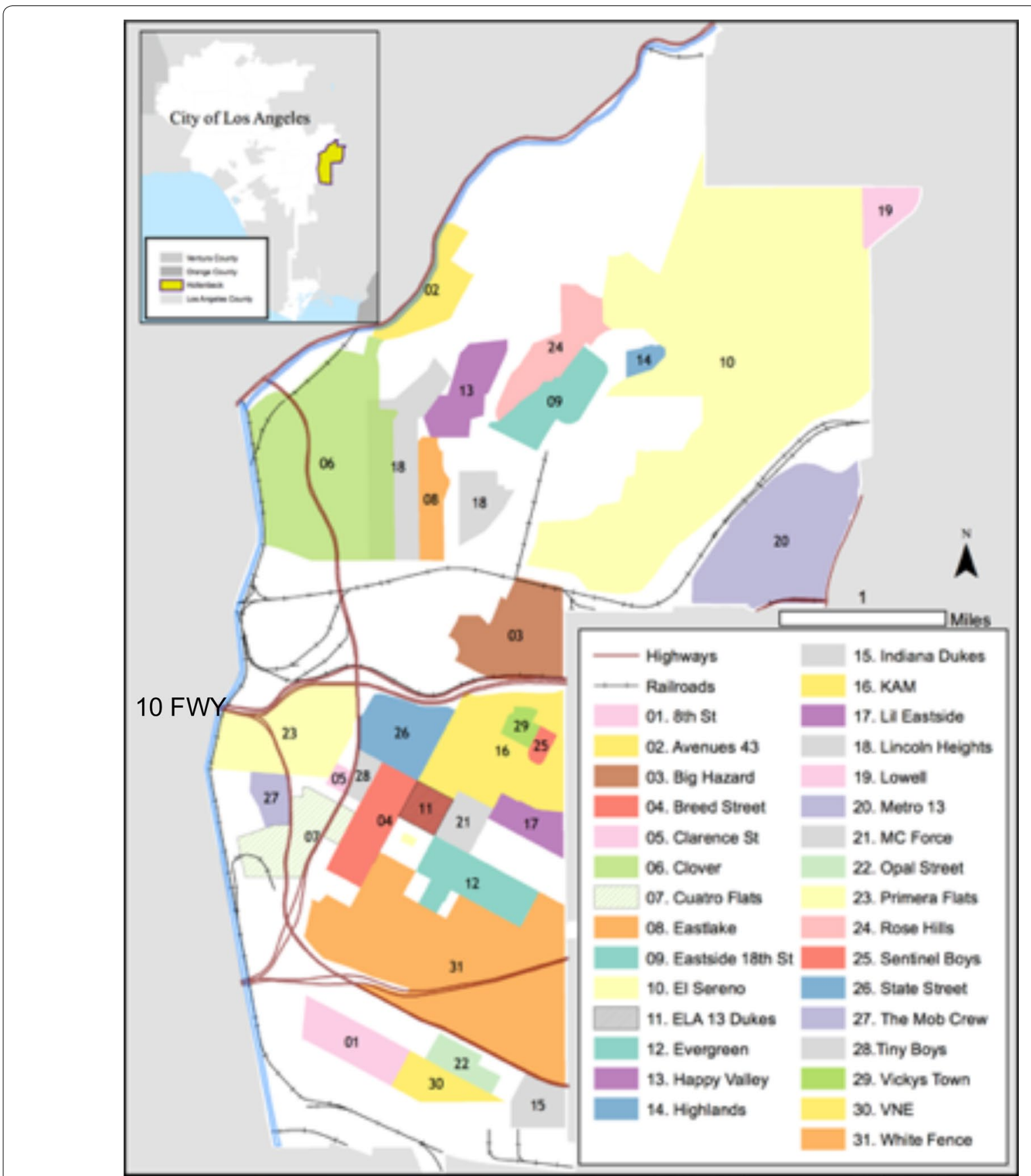

Fig. 6 Map of the LAPD Hollenbeck Policing Division with gang territories. The 10 Freeway traverses East-West across the middle of the map

Ideally, the competitive rank of a gang could be inferred by observing instances where activity by gang $i$ replaces the activity of gang $j$ (i.e., a top-down instance of a superior gang replacing and inferior one), or where gang $i$ attempts to engage in activity in a location where $j$ is present, but is ultimately unsuccessful (i.e., a bottom-up instance of an inferior gang trying to displace a superior one). Papachristos (2007) uses a coarsegrained analog of this approach to examine competition over territory among gangs in Chicago (see also Papachristos 2009). Inferring a top-down displacement event is confounded by the possibility that activity by gang $j$ might have ceased anyway. What would appear to be competitive displacement might actually 
Table 1 Gang size estimates and the in-and out-degree for the Hollenbeck gang homicide network 1990-2012

\begin{tabular}{|c|c|c|c|c|c|c|c|c|}
\hline Gang & $\begin{array}{l}\text { Gang turf size } \\
\left(10^{6} \text { square }\right. \\
\text { feet) }\end{array}$ & $\widehat{p}_{i}$ & $\begin{array}{l}\text { Total gang } \\
\text { members } \\
(2003)\end{array}$ & $\begin{array}{l}\text { Total gang } \\
\text { members } \\
\text { (2010) }\end{array}$ & $\begin{array}{l}\text { Observed } \\
\text { in-degree }\end{array}$ & $\begin{array}{l}\text { Observed } \\
\text { out-degree }\end{array}$ & $\begin{array}{l}\text { Expected } \\
\text { in-degree }\end{array}$ & $\begin{array}{l}\text { Expected } \\
\text { out-degree }\end{array}$ \\
\hline El Sereno & 71.78 & 0.16939233 & 338 & 425 & 19 & 12 & 18.99 & 12.01 \\
\hline White Fence & 32.27 & 0.076153392 & 675 & 611 & 10 & 10 & 9.18 & 9.89 \\
\hline Clover & 25.71 & 0.060672566 & 289 & 245 & 15 & 10 & 7.42 & 9.18 \\
\hline Metro 13 & 16.2 & 0.038230088 & 66 & 50 & 1 & 2 & 5.15 & 2.27 \\
\hline KAM & 13.54 & 0.031952802 & 289 & 240 & 8 & 15 & 3.87 & 10.23 \\
\hline Lincoln Heights & 12.236 & 0.028875516 & 122 & 161 & 7 & 11 & 3.54 & 9.36 \\
\hline Primera Flats & 10.4292 & 0.024611681 & 357 & 246 & 23 & 12 & 3.02 & 8.13 \\
\hline Big Hazard & 8.482 & 0.020016519 & 289 & 352 & 8 & 6 & 2.58 & 5.84 \\
\hline Cuatro Flats & 7.623 & 0.01798938 & 204 & 134 & 6 & 14 & 2.30 & 6.08 \\
\hline Breed Street & 6.53 & 0.015410029 & 137 & 84 & 11 & 10 & 2.00 & 5.23 \\
\hline Evergreen & 5.448 & 0.012856637 & 152 & 72 & 5 & 4 & 1.69 & 3.92 \\
\hline State Street & 5.298 & 0.012502655 & 156 & 92 & 8 & 11 & 1.65 & 4.34 \\
\hline Rose Hills & 5.292 & 0.012488496 & 48 & 37 & 5 & 7 & 1.63 & 4.31 \\
\hline Eastside 18th Street & 5.037 & 0.011886726 & 566 & 364 & 5 & 8 & 1.56 & 4.11 \\
\hline Avenues 43 & 4.576 & 0.01079882 & - & - & 2 & 3 & 1.43 & 2.99 \\
\hline 8th Street & 4.454 & 0.010510914 & 89 & 111 & 4 & 6 & 1.39 & 3.68 \\
\hline Happy Valley & 4.35 & 0.010265487 & 46 & 36 & 3 & 0 & 1.41 & 0.53 \\
\hline Eastlake & 3.096 & 0.007306195 & 168 & 145 & 11 & 14 & 0.98 & 2.59 \\
\hline VNE & 2.868 & 0.006768142 & 619 & 378 & 7 & 8 & 0.90 & 2.39 \\
\hline Lil Eastside & 2.52 & 0.005946903 & 60 & 48 & 3 & 2 & 0.80 & 1.98 \\
\hline Indiana Dukes & 2.486 & 0.005866667 & 98 & 85 & 2 & 2 & 0.79 & 1.98 \\
\hline Lowell & 2.315 & 0.005463127 & 58 & 27 & 4 & 11 & 0.73 & 1.93 \\
\hline Michigan Criminal Force & 2.036 & 0.00480472 & 84 & 107 & 5 & 4 & 0.65 & 1.72 \\
\hline Opal Street & 1.997 & 0.004712684 & 80 & 57 & 4 & 4 & 0.64 & 1.69 \\
\hline The Mob Crew & 1.784 & 0.004210029 & 152 & 141 & 12 & 11 & 0.57 & 1.51 \\
\hline ELA 13 Dukes & 1.63 & 0.003846608 & 317 & 191 & 7 & 10 & 0.52 & 1.37 \\
\hline Vicky's Town & 1.049 & 0.002475516 & 181 & 108 & 6 & 5 & 0.33 & 0.87 \\
\hline Tiny Boys & 0.9621 & 0.002270442 & 127 & 115 & 16 & 7 & 0.30 & 0.80 \\
\hline Highlands & 0.8886 & 0.002096991 & 31 & 21 & 1 & 1 & 0.28 & 0.73 \\
\hline Sentinel Boys & 0.6466 & 0.0015259 & 57 & 90 & 2 & 1 & 0.21 & 0.55 \\
\hline Clarence Street & 0.4487 & 0.001058879 & 117 & 64 & 4 & 4 & 0.14 & 0.36 \\
\hline Grand total & 263982200 & 0.622966842 & 5972 & 4837 & 224 & 225 & 76.65 & 122.59 \\
\hline
\end{tabular}

be activity spread into recently abandoned space. A bottom-up event might be more reliable for inferring competitive ranking, but the chance of observing such an event seems low. If activity spread is accompanied by some measure of conflict, then the case for inferring competitive displacement would be much better. Field interview data aligned with violent crime data could provide such insights.

We are potentially in a better position to measure competitive interactions through the record of crimes occurring between gangs. Figure 7 shows a homicide network for Hollenbeck gangs over a 23 year period between 1990 and $2012(N=395)$. Nodes in the network represent each of the 31 gangs in Hollenbeck with node size scaled according to estimated gang territory size $\widehat{p}_{k}$ (Table 1 ). Edges are directed from the aggressor gang to the targeted gang, as identified in police records, and there is one edge drawn for each directional homicide recorded in the dataset (see Valasik et al. 2017). Homicides within the same gang (i.e., self-loops) are excluded from the analyses.

\section{Empirical comparisons}

Figure $8 \mathrm{a}$ shows that the neither the number of homicides targeting a gang (in-degree, $t=3.17, p=0.004$, $\left.r^{2}=0.26\right)$, nor the number of homicides perpetrated 


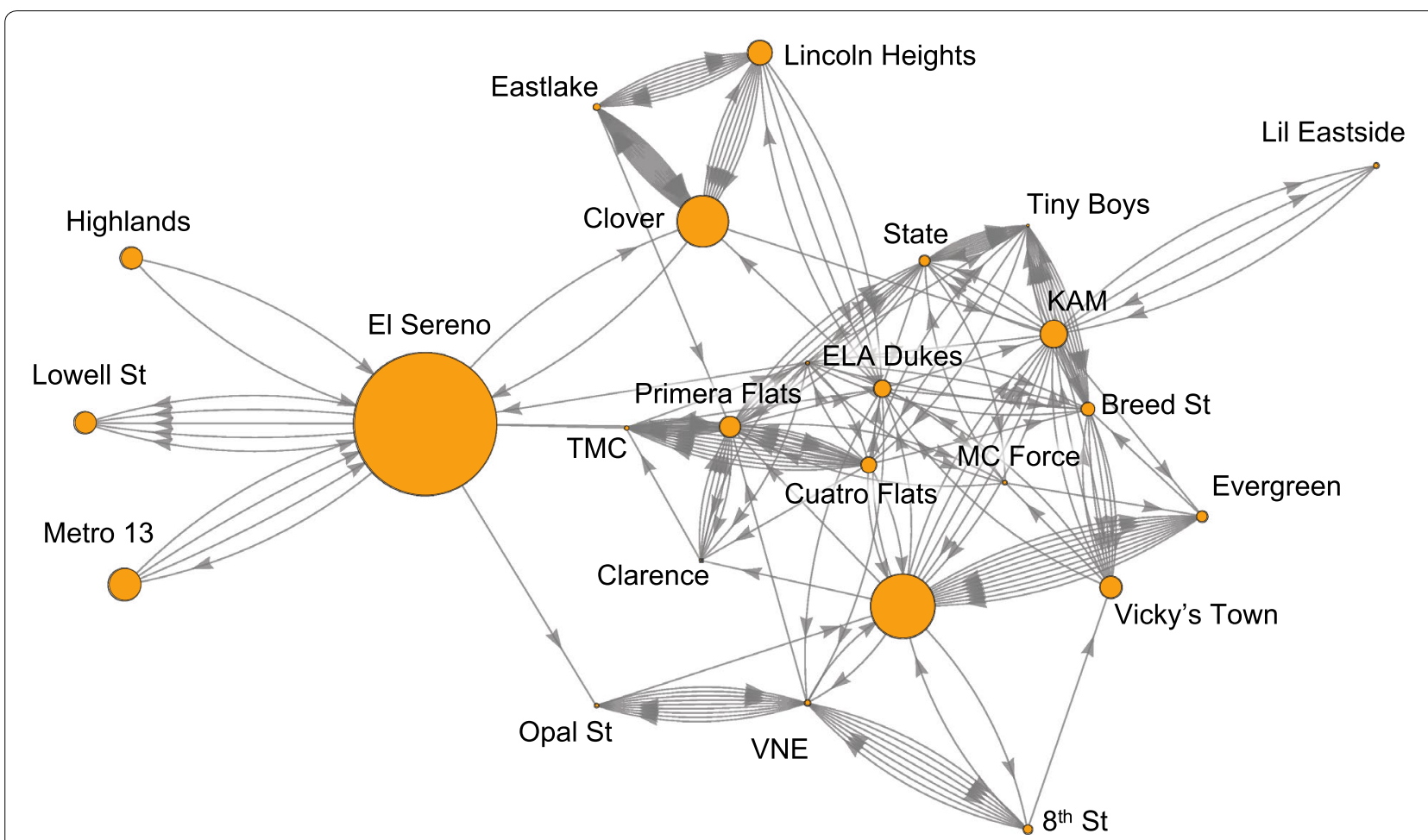

Fig. 7 Homicide network for Hollenbeck gangs. Directed edges point to the targeted gang. Data includes all between-gang homicides from 1990 to 2012. Network nodes are scaled by territory size (see Table 1)

by an aggressor gang (out-degree, $t=1.94, p=0.06$, $\left.r^{2}=0.11\right)$ is strongly correlated with territory size. Combined in- and out-degree is also not strongly correlated with combined in- and out-degree $(t=2.91, p=0.007$, $\left.r^{2}=0.22\right)$. Figure $8 \mathrm{~b}$ suggests that homicide in- and outdegree are more strongly correlated with one another $\left(t=4.52, p<0.001, r^{2}=0.41\right)$.

Visual inspection of Fig. 8b, prompts us to reject the hypothesis that a stable competitive hierarchy among Hollenbeck gangs could be the result of variable activity cessation rates $m_{i}$ with constant activity spread rates $c_{i}=c$. The simple fact that the Hollenbeck gangs do not display perfect balance in their in- and out-degree, as seen in Fig. 5b, supports this conclusion. The observed data are visually more consistent with the hypothesis that Hollenbeck gangs emphasize variable activity spread rates to ensure survival as seen in Fig. 5 a.

Figure 9 shows simulated competitive hierarchies for all thirty-one Hollenbeck gangs listed in Table 1. As above, simulation is necessary due to the large number of unknown parameters (i.e., competitive rank, spread and cessation rates). Our simulation procedure is equivalent to that used to generate Fig. 5a: (1) randomly order the $k$ Hollenbeck gangs into a hypothetical competitive hierarchy; (2) assign a fixed activity cessation rate $m_{i}=m=0.6$ to each gang; (3) compute the value of $c_{i}$ sufficient to achieve the observed value of $\widehat{p}_{k}$ in Table 1 , using a rearranged version of Eq. (13); (3) compute the expected in- and out-degree using Eqs. (14) and (15); and (4) rescale the simulation results to reflect expected inand out-degree in units of numbers of homicides. ${ }^{2} \mathrm{We}$ repeat these four steps 5000 times to sample the space of possible competitive hierarchies. Table 2 provides a numerical example for a single iteration to use in verifying computations. Table 1 list the expected in- and outdegree for each gang obtained in simulation.

Figure 9a confirms the visual impression that homicide in- and out-degrees for Hollenbeck gangs generally fall within the expected range generated by theory under the assumed parameter values and scaling. The gangs that are

\footnotetext{
${ }^{2}$ The theoretical in- and out-degrees need to be scaled to compare with the observed in- and out-degrees. We use a fixed dilation constant of $D=140.9135$ applied equally to simulated in- and out-degrees to produce expected in- and out-degrees in number of homicides. The dilation constant is chosen such that the observed in- and out-degree for the El Sereno gang, the largest by territory proportion, intersects with the theoretical curve computed for the El Sereno equilibrium territorial proportion. Note in Fig. 9a how the centroid for the El Sereno bubble falls exactly along the transecting curve generated by simulation. All other transecting curves use the El Sereno scaling.
} 


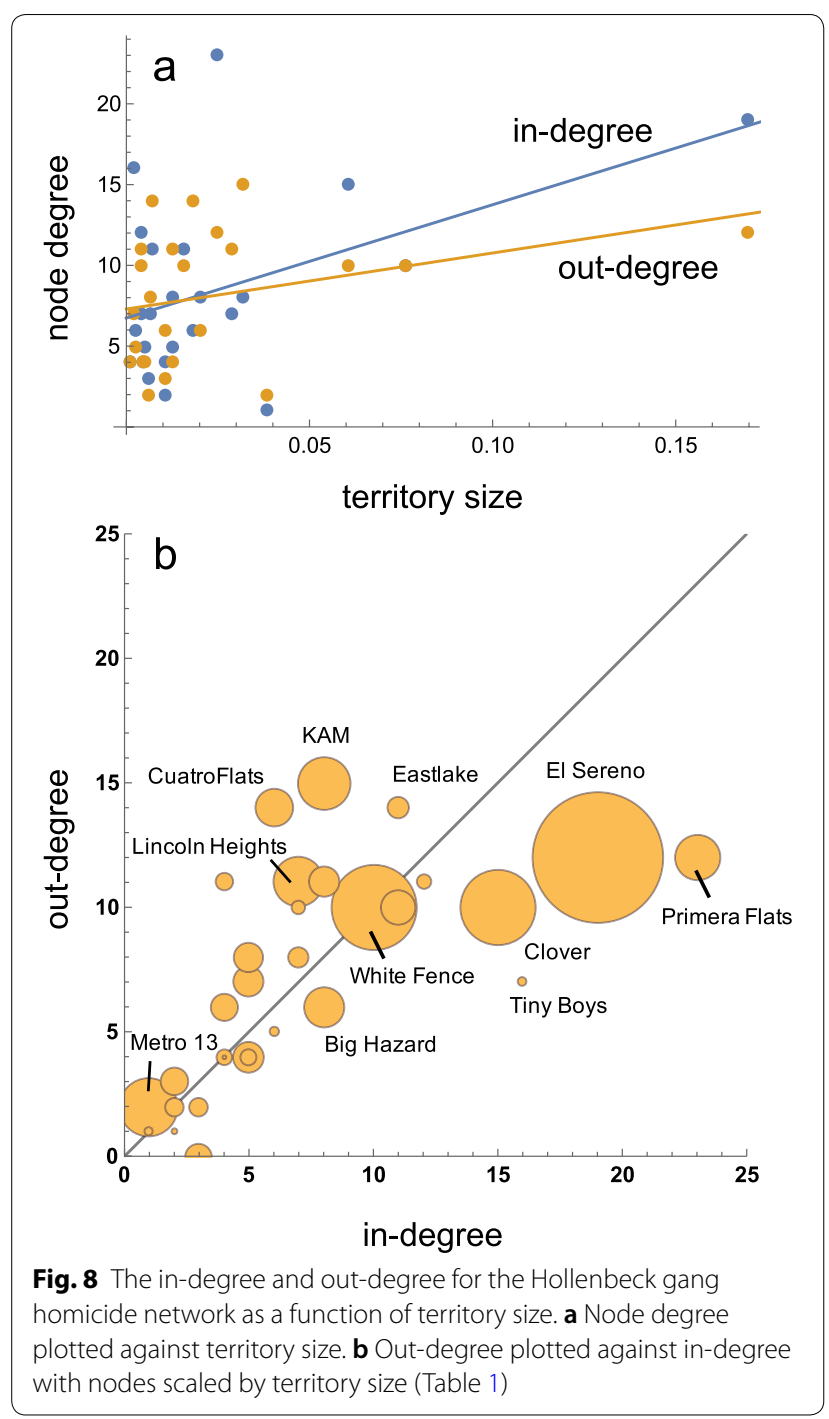

net importers of violence (e.g., El Sereno) are expected to rank towards the top of the community competitive hierarchy. Those that are net exporters of violence (e.g., Cuatro Flats, KAM, East Lake) are expected to rank towards the bottom of the competitive hierarchy. The greater the deviation from a balanced degree distribution the more extreme a gang's position in the competitive hierarchy. Table 1 shows that 16 of the 31 gangs (51.6\%) display observed in- or out-degrees that are within three homicides of the expected values. El Sereno is excluded from this count since the simulations are scaled to be consistent with this gang.

There are some glaring mismatches between the theory and observed data (Table 1). First, there is poor numerical agreement between expected and observed in- and out-degrees. Table 1 shows that 13 of 31 gangs (41.9\%) gangs display in- or out-degrees that are at least five homicides in error. Four gangs (12.9\%) are at least 10 homicides in error. Second, it is clear that the expected regular ordering of gangs by territory size does not hold. El Sereno is positioned where you would expect to see a high-ranked, large gang. By contrast, the position of Primera Flats, to the right of El Sereno, with a high indegree and moderately high out-degree, seems inconsistent with its observed territory size. Theory would predict Primera Flats to have either a much larger territory size (larger than El Sereno), or a much lower in-degree that would place it closer to Lincoln Heights or Big Hazard (see Fig. 8b). The discrepancy is also glaring for the Tiny Boys gang. It appears to be a target of violence consistent with a gang with high competitive rank (high in-degree), but it displays a territory size that is at least an order of magnitude too small for such a status. On the other end of the spectrum, the Metro 13 gang appears to have a homicide degree distribution consistent with a small, low-ranked gang. However, it has a relatively large territory size that would anticipate it being both the aggressor in and target of much more violence.

To explore whether the models can plausibly generate such deviations in territory sizes we introduce a further simulation step. Rather than assigning a constant activity cessation rate to each gang in Step 2 of the simulation, we assign $m_{i}$ randomly to each gang over a range between 0.3 and 0.8 for each iteration. ${ }^{3}$ The parameter range is arbitrary, but implies that a gang ceases activity at $30-80 \%$ of all sites in any instant in time. Figure 9b shows that introducing variation in activity cessation rates induces a wider range of homicide in- and out-degrees. But the added variation is not sufficient to encompass the most extreme outliers in territory size such as Primera Flats or Tiny Boys. It is possible that more complete exploration of parameter space would find somewhat better alignment between the models and observed data. It seems more appropriate, however, to suggest revisions to the model that take into account more realistic behavioral and environmental effects.

\section{Discussion and conclusions}

We started this paper by highlighting the fact that competitive interactions between rival gangs often appear imbalanced. Some gangs are net exporters of violence (i.e., more often aggressors in homicides), while others are net importers (i.e., more often targets in homicides). It is reasonable to suppose that such imbalances in violence reflect imbalances in competitive ability since

\footnotetext{
${ }^{3}$ A technical observation is that mixtures of activity cessation and spread rates produce viable solutions to Eq. 12 , for the empirical array of $\widehat{p}_{k}$, only if random cessation rates $m_{i}$ are chosen first and spread rates $c_{i}$ are computed after. If random activity spread rates are chosen first, then $m_{i}>0$ cannot be found for some significant fraction of gangs.
} 

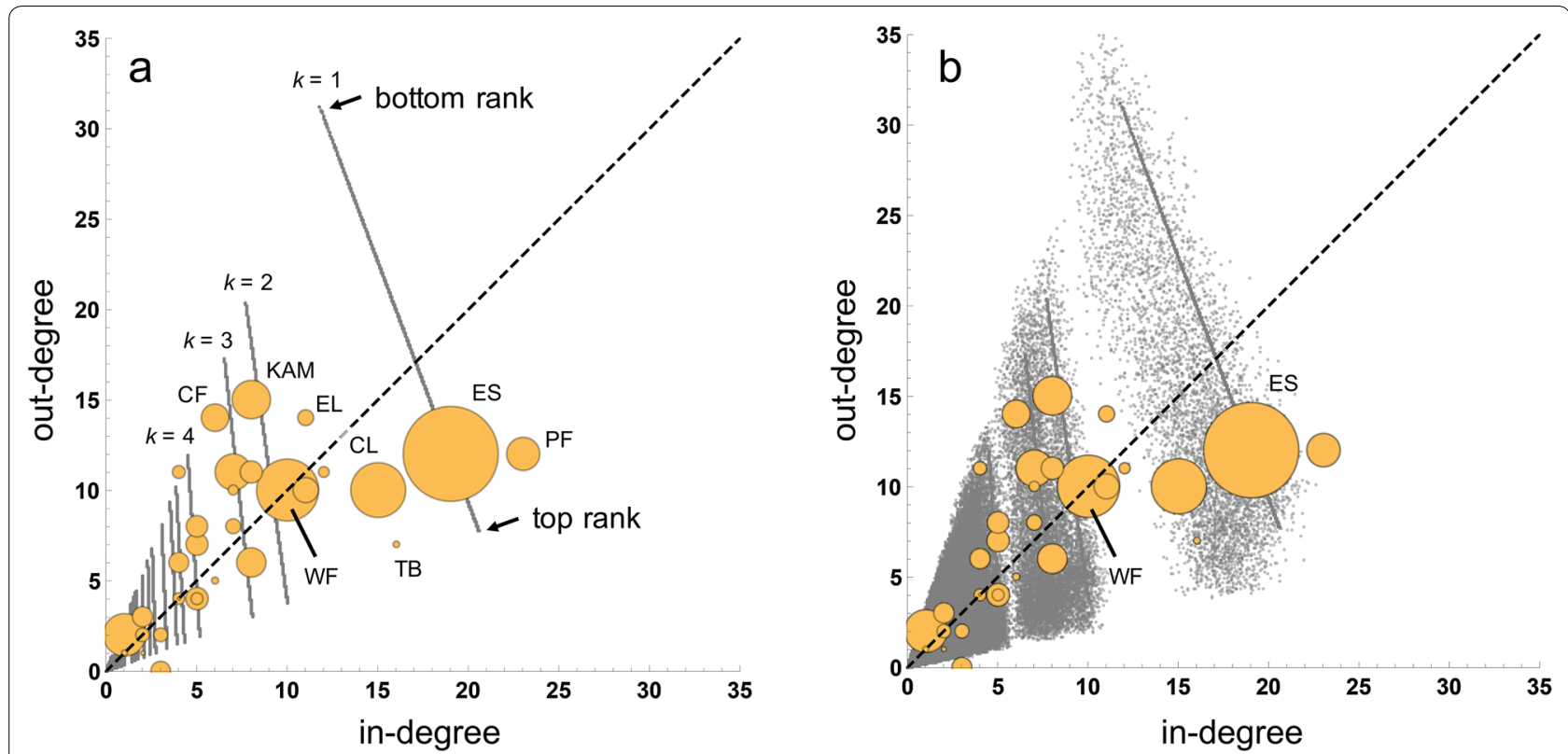

Fig. 9 The distribution of in- and out-degree for Hollenbeck gangs superimposed upon 5000 simulated gang communities. a The competitive hierarchy is randomized in each simulation and the expected in- and out-degree at equilibrium is computed for each gang. Change in the rank position of a gang causes it to shift in- and out-degree, but the gangs remain distributed in order of their territory size. b The competitive hierarchy is randomized and then activity cessation rates over a range 0.3-0.8 are assigned randomly to each gang. In- and out-degree display more range over simulated communities, but not enough to explain the inversions in territory sizes. Simulation results are scaled so that observed and expected in- and out-degree for El Sereno intersect. Gangs: Clover (CL); Cuatro Flats (CF); Eastlake (EL); El Sereno (ES); Primera Flats (PF); Tiny Boys (TB); White Fence (WF)

violence appears central to how gangs "jockey for positions of dominance" (Papachristos 2009, p. 76). Exactly how these dynamics unfold remains an open question, however, since we do not have formal expectations about how competitive dominance, gang size and directionality of violence should be related.

To rectify this situation, we turned to mathematical models first developed to deal with analogous problems observed in plant ecology (Tilman 1994). The key advantage of Tilman's model is that it allows us to make strict assumptions about competitive dominance and follow those assumptions through to their empirical expectations. The key assumption is that a superior competitor can always displace an inferior competitor wherever they are encountered and always hold a site against any incursion by an inferior competitor. Under such conditions inferior competitors can persist if they can quickly exploit space as soon as it is vacated by superior competitors and/or if they can hold onto empty space longer before they are displaced. In essence, inferior competitors are able to survive in the "interstices" between superior competitors. We mapped Tilman's model onto the case of criminal street gangs by focusing on activity patterns. Many of our general observations parallel exactly those of Tilman. Our unique contribution was to extend the model to produce expectations about the relationships between competitive ability, gang size and the directionality of violence.

The model suggests that gang size, when measured as the proportion of space used by a gang, is not a simple proxy for a gang's competitive rank (see especially Figs. 2, 3). Gang size and competitive rank are only positively correlated if all gangs in a competitive hierarchy adopt a pure strategy for coexistence. That is, all of the gangs must either have identical activity cessation rates and leverage variable activity spread rates, or have identical activity spread rates and leverage variable activity cessation rates. If individual gangs adopt mixed strategies, then gang size fails to track competitive rank. The largest gangs can be competitively inferior and the smallest competitive superior in terms of absolute displacement ability. The models also suggest that the directionality of violence, as measured by the homicide in- and out-degree per gang, is also not a simple proxy for competitive rank (see especially Fig. 5). Large gangs typically experience more overall violence (cumulative in- and out-degree), compared with small gangs. However, variation in competitive rank (and random noise in activity cessation and 
Table 2 Numerical results for one simulated gang community

\begin{tabular}{|c|c|c|c|c|c|c|}
\hline Rank & Gang name & $\widehat{p}_{k}^{a}$ & $m_{i}$ & $c_{i}$ & Unscaled in-degree $^{b}$ & Unscaled out-degree \\
\hline 1 & Cuatro Flats & 0.0179 & 0.6 & 0.610936 & 0.0174319 & 0.00659973 \\
\hline 2 & Eastlake & 0.0073 & 0.6 & 0.626729 & 0.00715554 & 0.00280958 \\
\hline 3 & Breed Street & 0.0154 & 0.6 & 0.641558 & 0.0150136 & 0.00598728 \\
\hline 4 & Happy Valley & 0.0102 & 0.6 & 0.658861 & 0.00997627 & 0.0041075 \\
\hline 5 & MC Force & 0.0048 & 0.6 & 0.669326 & 0.00471155 & 0.00198099 \\
\hline 6 & State Street & 0.0125 & 0.6 & 0.681751 & 0.0122033 & 0.00518898 \\
\hline 7 & Metro 13 & 0.0382 & 0.6 & 0.720427 & 0.0365676 & 0.0160499 \\
\hline 8 & Eastside 18th Street & 0.0118 & 0.6 & 0.761273 & 0.0115145 & 0.00547605 \\
\hline 9 & Big Hazard & 0.02 & 0.6 & 0.78936 & 0.01938 & 0.00949442 \\
\hline 10 & White Fence & 0.0761 & 0.6 & 0.885895 & 0.0698118 & 0.0367623 \\
\hline 11 & 8th Street & 0.0105 & 0.6 & 0.984849 & 0.0102317 & 0.00631726 \\
\hline 12 & Vicky's Town & 0.0024 & 0.6 & 1.00129 & 0.00235772 & 0.00148751 \\
\hline 13 & Lowell Street & 0.0054 & 0.6 & 1.01146 & 0.00528835 & 0.00336453 \\
\hline 14 & Evergreen & 0.0128 & 0.6 & 1.03585 & 0.0124355 & 0.00806938 \\
\hline 15 & ELA 13 Dukes & 0.0038 & 0.6 & 1.05875 & 0.0037269 & 0.00248477 \\
\hline 16 & Indiana Dukes & 0.0058 & 0.6 & 1.07239 & 0.00567568 & 0.00382896 \\
\hline 17 & Lincoln Heights & 0.0288 & 0.6 & 1.1242 & 0.0274294 & 0.0191865 \\
\hline 18 & Rose Hills & 0.0124 & 0.6 & 1.19 & 0.0120284 & 0.00898637 \\
\hline 19 & Opal Street & 0.0047 & 0.6 & 1.2191 & 0.00460156 & 0.00353355 \\
\hline 20 & Sentinel Boys & 0.0015 & 0.6 & 1.22993 & 0.00147441 & 0.00114365 \\
\hline 21 & El Sereno & 0.1693 & 0.6 & 1.6275 & 0.120076 & 0.124569 \\
\hline 22 & Tiny Boys & 0.0022 & 0.6 & 2.15793 & 0.00215608 & 0.00293962 \\
\hline 23 & Lil Eastside & 0.0059 & 0.6 & 2.19153 & 0.00573395 & 0.00795842 \\
\hline 24 & Avenues 43 & 0.0107 & 0.6 & 2.26291 & 0.0102781 & 0.014787 \\
\hline 25 & Clover & 0.0606 & 0.6 & 2.62226 & 0.0500482 & 0.0891161 \\
\hline 26 & VNE & 0.0067 & 0.6 & 3.02126 & 0.00646244 & 0.012443 \\
\hline 27 & Highlands & 0.002 & 0.6 & 3.08096 & 0.00195725 & 0.00381669 \\
\hline 28 & Clarence Street & 0.001 & 0.6 & 3.102 & 0.00098168 & 0.00192448 \\
\hline 29 & KAM & 0.0319 & 0.6 & 3.3525 & 0.0280031 & 0.063044 \\
\hline 30 & Primera Flats & 0.0246 & 0.6 & 3.84732 & 0.0218975 & 0.0564836 \\
\hline 31 & TMC & 0.0042 & 0.6 & 4.13998 & 0.00406307 & 0.0107318 \\
\hline
\end{tabular}

a The notation $\widehat{p}_{k}$ is used to emphasize that the equilibrium proportions are in a random order independent of the competitive rank of the gang

${ }^{\text {b }}$ A dilation constant $D=140.9135$ may be used to convert unscaled to scaled expected degrees. See Note 2

spread rates) can cause a gang to flip from being a netimporter to a net exporter of violence.

We examined the implications of the models using homicide data from LAPD's Hollenbeck Community Policing Area. Territory size is not strongly correlated with the directionality of violence between rivals, as measured by in- and out-degree over the homicide network. Territory size is only marginally better at predicting the total volume of violence. The model presented here suggests that we should not be surprised by this result as competitive ability, gang size and directionality of violence need not be strongly connected, even where absolute competitive dominance exists. The observed in- and out-degrees for the
Hollenbeck homicide network is perhaps more consistent with gangs leveraging faster activity spread rates to circumvent competitive asymmetries than an alternative model of slower activity cessation rates. However, we have not performed rigorous model evaluation as there remain many unknowns that deserve further theoretical discussion (see below). Nevertheless, it is reasonable to hypothesize that gangs such as El Sereno, and perhaps Clover, are net importers of violence as a result of large size and relatively high-rank in competitive ability. By contrast, gangs such as KAM and Lincoln Heights may be net-exporters of violence because of an intermediate size and relatively low competitive rank. However, there are gangs that do not neatly 
align with model expectations. These outliers either have observed in-degrees that are much larger than expected for the small territory size (e.g., Primera Flats, Tiny Boys), or much smaller than expected for their large territory size (e.g., Metro 13). Assuming that the in- and out-degree counts are accurate, alignment with model expectations would require that territory sizes be adjusted upwards or downwards.

\section{Limitations}

This study has several important limitations. First, the use of homicide data may not be the best metric to assess gang dominance given that these acts of violence are likely rare when compared to other less severe options that may accomplish much the same thing (e.g., aggravated or simple assault). However, since most acts of gang-related violence involve firearms (Huebner et al. 2016; Maxson et al. 1985; Maxson and Klein 1990; Pizarro 2017; Rosenfeld et al. 1999; Valasik 2014), the only difference between a gang-related homicide and a gang-related aggravated assault may be random. Thus, more dominant gangs may attempt to utilize less severe acts of violence, however, the results may still be a homicide. Furthermore, research has shown that the investigation of homicides by law enforcement is likely to be the most robust, given that there is almost always a victim, with a specialized police unit that dedicates substantially more investigative time and effort to their resolution (Petersen 2017; Pizarro et al. 2018; Regoeczi 2018). In this study, the thoroughness of investigating gangrelated homicide is expected to provide a much more complete picture of the violent event including reliable data on gang affiliations of both the target and the aggressor, two crucial pieces of information needed to the current analyses. As such, the use of gang-related homicides as the sole metric of violence is likely to be conservative measure.

It is premature to conclude that territory size is not at all a useful predictor of competitive rank. Part of the problem may be with the way that gang territories are recognized and measured in real-world settings. Recording gang territories as bounded, convex polygons may be pragmatic. However, there is good reason to question whether this is a realistic representation of the distribution of gang activity, gang areal control or gang competitive position. It has long been recognized that gangs may claim a large swath of land, but that most hanging out occurs at only a handful of locations, termed 'set spaces' by Tita et al. (2005). In fact, Valasik (2018) finds that areas with high concentrations of gang member residences and gang set space locations are most at risk of experiencing a gang-related homicide. It might be more appropriate to think of gang territories as a network of placed-based activity nodes and corridors or pathways between them. This would be a group-level analog of crime pattern theory (Brantingham and Brantingham 1993). Some nodes and corridors might be common to the gang as a whole (i.e., set spaces), while others might be tied to the activities of single gang members (e.g., gang member residences). Gang territories seem to overlap quite substantially when drawn as convex polygons. For example, in the entire city of Los Angeles approximately $40 \%$ of all documented gang turfs overlap according to 2010 gang territory maps. However, if territories are really a "mesh" of shifting nodes and corridors between them, then the actual equilibrium size distribution of gangs may be quite different from (and lower) than that measured using territory maps.

This concern over defining territories raises a related issue about modeling both spatial and temporal patterns of gang behavior. The models presented above are spatially implicit. They deal only with the proportion of space occupied by a gang, not the actual spatial arrangement of those gangs. The models do imply, however, that the spatial arrangements of gangs are subject to constant change. Even though gangs occupy a stable proportion of the landscape at equilibrium, there is regular turnover in which gangs occupy which sites. Such change is not consistent with the "turf-as-polygon" view of gang territoriality. It may be more consistent with the idea that gang territories are a shifting mesh of nodes and corridors. Spatially implicit models also do not take into consideration any constraints of mobility (Hubbell 2005; Turchin 1998). How far people move plays an important role in the generation of crime patterns (Brantingham and Tita 2008) and presumably plays and important role in the formation and maintenance of gang territories (Brantingham et al. 2012; Hegemann et al. 2011; Valasik and Tita 2018). Including mobility in the current model would require a spatially explicit approach. Such models are much more challenging mathematically, but frequently lead to novel insights quite different from spatially implicit models (Kareiva and Wennergren 1995; Tilman et al. 1994). Thus, it is premature to claim that faster activity spread rates will be a decisive property in a spatially explicit systems of gangs.

The models developed here offer only a limited view of competitive dynamics. We recognize that it is extreme to assume that gangs form a strict competitive hierarchy. This assumption is theoretically valuable as a form of counterfactual. It is much more likely, however, that competitive ability is context dependent (Hubbell 2005). Who has the upper hand in any one dyadic interaction may depend as much on where an interaction takes place, or who is present, as on some global competitive ability of the gang. A more detailed assessment of the costs and 
benefits that arise in competitive interactions across contexts is needed. For example, it is perhaps unrealistic to assume that inferior gangs will continue to attack superior gangs if such attacks never yield successful displacements. The contexts in which attacks are successful and unsuccessful may carry great importance for understanding competitive dynamics.

A related concern is whether it is reasonable to model a community of gangs as a single competitive hierarchy. Competitive interactions may be restricted to smaller clusters of gangs that exist in close spatial proximity to one another. A broader community of gangs may in fact be best modeled as a multiscale system composed of several competitive hierarchies that sometimes interact. These concerns again point us in the direction of spatially explicit models where the competitive ranking of gangs may shift across the landscape. It also suggests a role for game theory in modeling competition as strategic interactions that might include behavior other than acting as a superior (or inferior) competitor. Specifically, we believe it will be important to relax the assumption that activity spread and cessation rates for each gang are unchanging in time. These traits, if important, presumably would be under heavy selection via some learning mechanism. Inferior gangs might be put at an even greater disadvantage if superior gangs seek to close off spatial opportunities in response to competitive interactions by evolving their activity spread and cessation rates. These possibilities will require further examination.

\section{Abbreviations}

CL: Clover; CF: Cuatro Flats; EL: Eastlake; ES: El Sereno; PF: Primera Flats; TB: Tiny Boys; WF: White Fence.

\section{Acknowledgements}

We are grateful for the comments of the anonymous referees for suggestions.

\section{Authors' contributions}

MV collected the empirical data. PJB, MV and GET conducted the analyses and wrote the paper. All authors read and approved the final manuscript.

\section{Funding}

US National Science Foundation ATD [DMS-1737770]; and ONR N00014-17-1-2281

\section{Data availability}

Raw data on gang homicides were collected under a non-disclosure agreement with the Los Angeles Police Department. In addition to summary measures presented in the paper, the adjacency matrix for the homicide graph is available upon request.

\section{Competing interests}

The authors declare that they have no competing interests.

\section{Author details}

${ }^{1}$ Department of Anthropology, University of California Los Angeles, 341 Haines Hall, Los Angeles, CA 90095, USA. ${ }^{2}$ Department of Sociology, Louisiana State University, 17B Stubbs Hall, Baton Rouge, LA 70803, USA. ${ }^{3}$ Criminology, Law and Society, University of California Irvine, Social Ecology II, 2307, Irvine, CA 92697, USA.
Received: 10 April 2019 Accepted: 7 August 2019

Published online: 30 August 2019

\section{References}

Bannister, J., Kintrea, K., \& Pickering, J. (2013). Young people and violent territorial conflict: exclusion, culture and the search for identity. Journal of Youth Studies, 16(4), 474-490. https://doi.org/10.1080/13676261.2012.725835.

Bichler, G., Norris, A., Dmello, J. R., \& Randle, J. (2017). The impact of civil gang injunctions on networked violence between the bloods and the crips. Crime \& Delinquency, 65(7), 875-915.

Block, R. (2000). Gang activity and overall levels of crime: A new mapping tool for defining areas of gang activity using police records. Journal of Quantitative Criminology, 16(3), 369-383.

Brantingham, P. L., \& Brantingham, P. J. (1993). Nodes, paths and edges: Considerations on the complexity of crime and the physical environment. Journal of Environmental Psychology. https://doi.org/10.1016/s0272 $-4944(05) 80212-9$.

Brantingham, P. J., \& Tita, G. (2008). Offender mobility and crime pattern formation from first principles. In L. Liu \& J. Eck (Eds.), Artificial crime analysis systems: using computer simulations and geographic information systems (pp. 193-208). Hershey, PA: Idea Press.

Brantingham, P. J., Tita, G. E., Short, M. B., \& Reid, S. E. (2012). The ecology of gang territorial boundaries. Criminology, 50(3), 851-885.

Bubolz, B. F., \& Lee, S. (2018). Putting in work: The application of identity theory to gang violence and commitment. Deviant Behavior, 40(6), 690-702. https://doi.org/10.1080/01639625.2018.1437655.

Decker, S. H. (1996). Collective and normative features of gang violence. Justice Quarterly, 13, 243-264.

Densley, J. A., Cai, T., \& Hilal, S. (2014). Social dominance orientation and trust propensity in street gangs. Group Processes \& Intergroup Relations, 17 , 763-779.

Faust, K., \& Tita, G. E. (2009). Social networks and Crime: pitfalls and promises for advancing the field. Annual Review of Criminology, 2(1), 99-122.

Glowacki, L., Isakov, A., Wrangham, R. W., McDermott, R., Fowler, J. H., \& Christakis, N. A. (2016). Formation of raiding parties for intergroup violence is mediated by social network structure. Proceedings of the National Academy of Sciences, 113(43), 12114-12119. https://doi.org/10.1073/ pnas. 1610961113

Grannis, R. (2009). From the ground up: Translating geography into community through neighbor networks. Princeton: Princeton University Press.

Gravel, J., Allison, B., West-Fagan, J., McBride, M., \& Tita, G. E. (2018). Birds of a feather fight together: Status-enhancing violence, social distance and the emergence of homogenous gangs. Journal of Quantitative Criminology, 34(1), 189-219.

Gustafson, C. V. (1940). An ecological analysis of the Hollenbeck area of Los Angeles. California: University of Southern California.

Hegemann, R. A., Smith, L. M., Barbaro, A. B. T., Bertozzi, A. L., Reid, S. E., \& Tita, G. E. (2011). Geographical influences of an emerging network of gang rivalries. Physica A: Statistical Mechanics and its Applications, 390(21-22), 3894-3914. https://doi.org/10.1016/j.physa.2011.05.040.

Horowitz, R., \& Schwartz, G. (1974). Honor, normative ambiguity and gang violence. American Sociological Review, 39(2), 238-251. https://doi. org/10.2307/2094235

Hubbell, S. P. (2005). Neutral theory in community ecology and the hypothesis of functional equivalence. Functional Ecology, 19(1), 166-172. https://doi. org/10.1111/j.0269-8463.2005.00965.x.

Huebner, B. M., Martin, K., Moule, R. K., Jr., Pyrooz, D., \& Decker, S. H. (2016). Dangerous places: Gang members and neighborhood levels of gun assault. Justice Quarterly, 33(5), 836-862.

Hughes, L. A., \& Short, J. F. (2005). Disputes involving youth street gang members: Micro-social contexts. Criminology, 43(1), 43-76. https://doi.org/10.1 111/j.0011-1348.2005.00002.x.

Kareiva, P., \&Wennergren, U. (1995). Connecting landscape patterns to ecosystem and population processes. Nature, 373, 299. https://doi. org/10.1038/373299a0.

Lauger, T. R. (2012). Real gangstas: Legitimacy, reputation, and violence in the intergang environment. Rutgers: Rutgers University Press. 
Manson, S., Schroeder, J., Van Riper, D., \& Ruggles, S. (2018). IPUMS National Historical Geographic Information System: Version 13.0. Minneapolis: University of Minnesota.

Maxson, C. L., Gordon, M. A., \& Klein, M. W. (1985). Differences between gang and nongang homicides. Criminology, 23(2), 209-222.

Maxson, C. L., \& Klein, M. W. (1990). Street gang violence: Twice as great, or half as great? In C. R. Huff (Ed.), Gangs in America (pp. 71-100). Newbury Park, CA: Sage.

Melde, C., Taylor, T. J., \& Esbensen, F.-A. (2009). "I Got Your Back": An examination of the protective function of gang membership in adolescence. Criminology, 47(2), 565-594. https://doi.org/10.1111/j.1745-9125.2009.00148.x.

Miller, W. B. (1958). Lower class culture as a generating milieu of gang delinquency. Journal of Social Issues, 14(3), 5-19. https://doi. org/10.1111/j.1540-4560.1958.tb01413.x.

Mohler, G., Brantingham, P. J., Carter, J., \& Short, M. B. (2019). Reducing bias in estimates for the law of crime concentration. Journal of Quantitative Criminology, 33, 255-275.

Mohler, G. O., Short, M. B., \& Brantingham, P. J. (2017). The concentrationdynamics tradeoff in crime hot spotting. In D. Weisburd \& J. Eck (Eds.), Unraveling the crime-place connection: New directions in theory and policy (Vol. 22, pp. 27-48). New York: Routledge.

Nee, S., \& May, R. M. (1992). Dynamics of metapopulations: habitat destruction and competitive coexistence. Journal of Animal Ecology, 61(1), 37-40.

Papachristos, A. V. (2007). Murder by structure: A network theory of gang homicide. Unpbulished Ph.D. dissertation. University of Chicago, Department of Sociology.

Papachristos, A. V. (2009). Murder by structure: Dominance relations and the social structure of gang Homicide. American Journal of Sociology, 115(1), 74-128.

Papachristos, A. V., Braga, A. A., Piza, E., \& Grossman, L. S. (2015). The company you keep? The spillover effects of gang membership on individual gunshot victimization in a co-offending network. Criminology, 53(4), 624-649.

Papachristos, A. V., Hureau, D. M., \& Braga, A. A. (2013). The corner and the crew: The influence of geography and social networks on gang violence. American Sociological Review, 78(3), 417-447.

Petersen, N. (2017). Neighbourhood context and unsolved murders: The social ecology of homicide investigations. Policing and Society, 27(4), 372-392.

Pizarro, J. M. (2017). Gang Homicide in the United States: What We Know and Future Research Directions. In F. Brookman, E. R. Maguire, \& M. Maguire (Eds.), The handbook of homicide (pp. 73-88). Chichester, UK: Wiley.

Pizarro, J. M., Terrill, W., \& LoFaso, C. A. (2018). The impact of investigation strategies and tactics on homicide clearance. Homicide Studies. https://doi. org/10.1177/1088767918816741.

Randle, J., \& Bichler, G. (2017). Uncovering the social pecking order in gang violence. In B. LeClerc \& E. U. Savona (Eds.), Crime prevention in the 21st century: Insightful approaches for crime prevention initiatives (pp. 165-186). Cham: Springer International Publishing.

Ranker, J. E. (1957). A study of juvenile gangs in the Hollenbeck area of East Los Angeles. California: University of Southern California.

Regoeczi, W. C. (2018). Solving homicides: Understanding trends and patterns in police clearances of lethal violence. In W. C. Regoeczi (Ed.), Homicide and violent crime (pp. 121-138). Bradford: Emerald Publishing Limited.

Rosenfeld, R., Bray, T. M., \& Egley, A. (1999). Facilitating violence: A comparison of gang-motivated, gang-affiliated, and nongang youth homicides. Journal of Quantitative Criminology, 15(4), 495-516.
Short, J. F., \& Strodtbeck, F. L. (1965). Group process and gang delinquency. Chicago: University of Chicago Press.

Taniguchi, T. A., Ratcliffe, J. H., \& Taylor, R. B. (2011). Gang set space, drug markets, and crime around drug corners in Camden. Journal of Research in Crime and Delinquency, 48(3), 327-363.

Tilman, D. (1994). Competition and biodiversity in spatially structured habitats. Ecology, 75(1), 2-16.

Tilman, D., May, R. M., Lehman, C. L., \& Nowak, M. A. (1994). Habitat destruction and the extinction debt. Nature, 371, 65. https://doi.org/10.1038/37106 $5 \mathrm{a} 0$.

Tita, G. E., Cohen, J., \& Engberg, J. (2005). An ecological study of the location of gang "set space". Social Problems, 52(2), 272-299.

Tita, G. E., \& Radil, S. M. (2011). Spatializing the social networks of gangs to explore patterns of violence. Journal of Quantitative Criminology, 27(4), 521-545.

Tita, G., Riley, J. K., Ridgeway, G., Abrahamse, A. F., \& Greenwood, P. (2004). Reducing gun violence: Results from an intervention in East Los Angeles. Santa Monica, CA: RAND Press.

Turchin, P. (1998). Quantitative analysis of movement: Measuring and modeling population redistribution in animals and plants. Sunderland: Sinauer Associates.

Valasik, M. A. (2014). "Saving the World, One Neighborhood at a Time": The Role of Civil Gang Injunctions at Influencing Gang Behavior. Irvine: University of California.

Valasik, M. (2018). Gang violence predictability: Using risk terrain modeling to study gang homicides and gang assaults in East Los Angeles. Journal of Criminal Justice, 58, 10-21.

Valasik, M., Barton, M. S., Reid, S. E., \&Tita, G. E. (2017). Barriocide: Investigating the temporal and spatial influence of neighborhood structural characteristics on gang and non-gang homicides in East Los Angeles. Homicide Studies, 21(4), 287-311.

Valasik, M., \& Tita, G. (2018). Gangs and space. In S. D. Johnson (Ed.), The Oxford handbook of environmental criminology. Oxford: Oxford University Press.

van Gennip, Y., Hunter, B., Ahn, R., Elliott, P., Luh, K., Halvorson, M., et al. (2013). Community detection using spectral clustering on sparse geosocial data. Siam Journal on Applied Mathematics, 73(1), 67-83.

Vargas, R. (2016). Wounded City: Violent turf wars in a Chicago Barrio. New York: Oxford University Press.

Weisburd, D., Wyckoff, L. A., Ready, J., Eck, J. E., Hinkle, J. C., \& Gajewski, F. (2006). Does crime just move around the corner? A controlled study of spatial displacement and diffusion of crime control benefits. Criminology, 44(3), 549-592.

Weisburd, D. L., Groff, E. R., \& Yang, S.-M. (2012). The criminology of place: Street segments and our understanding of the crime problem. Oxford: Oxford University Press.

White, R. D. (2013). Youth gangs, violence and social respect: Exploring the nature of provocations and punch-ups. Basingstoke, UK: Palgrave McMillan.

\section{Publisher's Note}

Springer Nature remains neutral with regard to jurisdictional claims in published maps and institutional affiliations.

Ready to submit your research? Choose BMC and benefit from

- fast, convenient online submission

- thorough peer review by experienced researchers in your field

- rapid publication on acceptance

- support for research data, including large and complex data types

- gold Open Access which fosters wider collaboration and increased citations

- maximum visibility for your research: over $100 \mathrm{M}$ website views per year

At BMC, research is always in progress.

Learn more biomedcentral.com/submissions 